J Control Release. 2015 December 10; 219: 224-236. doi:10.1016/j.jconrel.2015.09.029.

\title{
Hybrid nanoparticles for combination therapy of cancer
}

\author{
Chunbai He, Jianqin Lu, and Wenbin Lin ${ }^{*}$ \\ Department of Chemistry, The University of Chicago, 929 E 57th Street, Chicago, IL 60637, USA
}

\begin{abstract}
Nanoparticle anticancer drug delivery enhances therapeutic efficacies and reduces side effects by improving pharmacokinetics and biodistributions of the drug payloads in animal models. Despite promising preclinical efficacy results, monotherapy nanomedicines have failed to produce enhanced response rates over conventional chemotherapy in human clinical trials. The discrepancy between preclinical data and clinical outcomes is believed to result from the less pronounced enhanced permeability and retention (EPR) effect in and the heterogeneity of human tumors as well as the intrinsic/acquired drug resistance to monotherapy over the treatment course. To address these issues, recent efforts have been devoted to developing nanocarriers that can efficiently deliver multiple therapeutics with controlled release properties and increased tumor deposition. In ideal scenarios, the drug or therapeutic modality combinations have different mechanisms of action to afford synergistic effects. In this review, we summarize recent progress in designing hybrid nanoparticles for the co-delivery of combination therapies, including multiple chemotherapeutics, chemotherapeutics and biologics, chemotherapeutics and photodynamic therapy, and chemotherapeutics and radiotherapy. The in vitro and in vivo anticancer effects are also discussed.
\end{abstract}

\section{Keywords}

Hybrid nanoparticle; co-delivery; synergistic effect; combination therapy of cancer

\section{Introduction}

Our understanding of cancer biology has significantly advanced in the past two decades [1], spurring much investment in the development of new cancer therapies. However, the survival rates for many common cancers have remained largely unchanged in the same period, calling for new and disruptive technologies for cancer treatment. Nanoparticle drug delivery potentially represents such a disruptive technology for enhancing therapeutic efficacies and reducing side effects by improving the pharmacokinetics and tumor deposition of the payloads via the enhanced permeability and retention (EPR) effect [1]. In animal models, the therapeutic efficacies of nanomedicines were further enhanced by attaching active targeting ligands on the particle surfaces to increase tumor selectivity and

\footnotetext{
*Corresponding author: wenbinlin@uchicago.edu; Tel: (+) 1773834 7163; Fax: (+) 17737020805.

Publisher's Disclaimer: This is a PDF file of an unedited manuscript that has been accepted for publication. As a service to our customers we are providing this early version of the manuscript. The manuscript will undergo copyediting, typesetting, and review of the resulting proof before it is published in its final citable form. Please note that during the production process errors may be discovered which could affect the content, and all legal disclaimers that apply to the journal pertain.
} 
drug deposition in cancer cells. Unfortunately, in the clinic, nanomedicines have largely failed to achieve better therapeutic outcomes of chemotherapeutic interventions.

A number of reasons have been proposed to account for the gap between preclinical animal results and clinical human trial data, including the less pronounced EPR effect in human tumors, the heterogeneity of human tumors, and the high propensity of developing resistance to therapies in human tumors. Several strategies have been pursued to overcome the barriers to delivering nanoparticles to human tumors, such as designing nanoparticles with superior pharmacokinetics [2] and multi-stage delivery systems [3] and enhancing the EPR effects using high intensity focused ultrasound (HIFU) [4] and X-ray radiation [5, 6]. Combination therapies provide a potential solution to addressing the tumor heterogeneity and drug resistance issues by taking advantage of distinct mechanisms of action of the multiple therapeutics/modalities to hit multiple targets and to overcome cross-resistance [7]. After a number of setbacks with monotherapies, several ongoing clinical trials are evaluating the therapeutic efficacy of combining chemotherapeutic nanomedicines with radiotherapy or small molecule drugs $[8,9]$.

To optimize their synergistic therapeutic effects, combination nanomedicines need to be rationally designed to accommodate multiple therapeutic drugs or modalities with temporally controlled release of individual cargoes. In this review, we will summarize the recent progress in the design of hybrid nanoparticles for combination therapy of cancers. Hybrid nanoparticles composed of both inorganic and organic components can be prepared using a number of strategies. The ability to combine a multitude of organic and inorganic components in hybrid nanoparticles in a modular fashion should allow for systematic tuning of their properties for combination cancer therapy. Optimally designed hybrid nanoparticles can combine the beneficial features of both purely inorganic nanomaterials (e.g., quantum dots (QDs) [10], gold nanoparticles [11], and metal oxides [12-14]) and purely organic nanoparticles (e.g., liposomes [15], dendrimers [16], micelles [17], and polymeric hydrogel nanoparticles [18]).

In this review, we will confine our discussion to four classes of hybrid nanomaterials: nanoscale coordination polymers (NCPs) and nanoscale metal-organic frameworks (NMOFs) that are built from metal ions or clusters bridged by organic linkers, polysilsesquioxane (PSQ) nanoparticles that are synthesized from condensation of silanolbased monomers, and inorganic nanoparticle/organic polymer composite systems that are prepared by mixing mesoporous silica, gold, or iron oxide nanoparticles with biodegradable polymers or biomacromolecuels. After briefly introducing synthetic strategies for various hybrid nanoparticles, we will discuss their recent applications in the co-delivery of multiple therapeutics/modalities to synergistically enhance the anticancer efficacy. We will only focus on combination therapy using multiple chemotherapeutics or by combining chemotherapy and other therapeutic modalities. We will also provide an outlook for potential clinical applications of hybrid nanoparticles. 


\section{Synthesis of hybrid nanomaterials}

\subsection{Synthesis of NCPs or NMOFs}

NMOFs and NCPs are a new class of molecular nanomaterials that are built from connecting metal ions or metal clusters with bridging ligands. In the past 15 years, bulk MOFs and coordination polymers have been extensively explored for various applications, such as gas storage and separations [19-23], nonlinear optics and ferroelectrics [24, 25], catalysis [26-31], sensing [32, 33], and light-harvesting and photocatalysis [34-37]. On the other hand, NMOFs/NCPs possess several interesting properties that make them potential nanocarriers for anticancer drug delivery: (1) compositional and structural tunability allows for the fine tuning of physicochemical properties of the nanoparticles; (2) highly porous and oriented structures accommodate efficient loading of diverse cargos; (3) intrinsic biodegradability due to the relatively labile metal-ligand bonds [38-44].

Four general methods have been utilized to synthesize NCPs or NMOFs: surfactant-free nanoprecipitation at room temperature and solvothermal reactions at elevated temperatures (Figure 1) and surfactant-based reverse microemulsion and solvothermal reactions (Figure 2). Amorphous particles from these reactions are called NCPs, while crystalline materials are categorized as NMOFs. Surfactants are used to control particle morphologies in reverse microemulsions and surfactant-templated solvothermal reactions.

In nanoprecipitation, precursor solutions are mixed to allow for particle nucleation and growth at room temperature. After the reaction, the resultant nanoparticles are precipitated out of the suspension by adding a poor solvent $[45,46]$. For example, the NCP composed of the anticancer prodrug $c, c, t-\mathrm{Pt}\left(\mathrm{NH}_{3}\right)_{2} \mathrm{Cl}_{2}$ (succinate) $)_{2}$ (disuccinatocisplatin, DSCP) and $\mathrm{Tb}^{3+}$ ions was synthesized by adjusting the $\mathrm{pH}$ value of an aqueous solution of $\mathrm{TbCl}_{3}$ and $\left[\mathrm{NMeH}_{3}\right]_{2} \mathrm{DSCP}$ to 5.5 , and adding methanol to the precursor solution to precipitate the NCP [45].

Surfactant-free solvothermal synthesis is carried out by heating a solution of metal ions and ligands to control particle nucleation and growth. For example, a crystalline $\mathrm{Fe}^{3+} \mathrm{NMOF}$ of the formula $\mathrm{Fe}_{3}\left(\mu_{3}-\mathrm{O}\right) \mathrm{Cl}\left(\mathrm{H}_{2} \mathrm{O}\right)(\mathrm{BDC})_{3}$ was synthesized by heating a solution of $\mathrm{FeCl}_{3}$ and terephthalic acid (BDC) with microwave [47]. This NMOF displayed octahedral morphology with a diameter of $200 \mathrm{~nm}$ and adopted a highly crystalline MIL-101 structure. In another example, the UiO NMOF of the formula of $\mathrm{Zr}_{6}\left(\mu_{3}-\mathrm{O}\right)_{4}\left(\mu_{3}-\mathrm{OH}\right)_{4}(\text { amino-TPDC })_{6}$ was synthesized by heating a DMF solution of $\mathrm{ZrCl}_{4}$ and amino-triphenyldicarboxylate (amino-TPDC) at $80^{\circ} \mathrm{C}$ for 5 days to afford hexagonal-plate particles with a diameter of $\sim 100 \mathrm{~nm}$ and a thickness of $\sim 30 \mathrm{~nm}[48]$.

In reverse microemulsions, surfactants are used to control nucleation and growth kinetics of particles. A crystalline $\mathrm{Gd}(\mathrm{BDC})_{1.5}\left(\mathrm{H}_{2} \mathrm{O}\right)_{2}$ nanorod was synthesized by mixing two microemulsions containing either $\mathrm{GdCl}_{3}$ or $\left[\mathrm{NMeH}_{3}\right]_{2}[\mathrm{BDC}]$ [49]. The particle morphologies could be controlled by adjusting the water to surfactant molar ratio ( $w$ value) of the microemulsion. More recently, $30 \mathrm{~nm}$ Zn-bisphosphonate NCPs containing the cisplatin prodrug ( $\mathrm{Zn}$-cis) and oxaliplatin prodrug ( $\mathrm{Zn}$-oxali) were synthesized by vigorously stirring a mixture of $\mathrm{Zn}\left(\mathrm{NO}_{3}\right)_{2}$ and corresponding prodrugs in the presence of 1,2-dioleoyl- 
sn-glycero-3-phosphate sodium salt (DOPA) in the Triton X-100/1-hexanol/cyclohexane/ water reverse microemulsions [50].

Surfactant molecules can be used to template the NMOF synthesis under solvothermal conditions. For example, a reverse microemulsion of $\mathrm{GdCl}_{3}$ and $\left[\mathrm{NMeH}_{3}\right]_{6}[\mathrm{BHC}]$ (BHC=benzene hexacarboxylic acid) was heated at $120^{\circ} \mathrm{C}$ to afford block-like crystalline Gd-BHC NMOFs of $25 \times 50 \times 100 \mathrm{~nm}$ in dimensions [49]. This method was also used to synthesize other DOPA-capped NCPs and NMOFs, including Zr-methotrexate (MTX) NMOFs, Zn-MTX NMOFs, and La-DSCP NCPs [46, 51].

By taking advantage of the porous $\mathrm{NMOF} / \mathrm{NCP}$ structure and the functionality of bridging ligands, several different strategies have been adopted to incorporate high loadings of therapeutic agents into NMOFs/NCPs. The therapeutic agents were loaded either by direct incorporation as metal connecting points/clusters or as the bridging ligand during $\mathrm{NMOF} / \mathrm{NCP}$ synthesis or via post-synthetic loading into the pores and channels in the NMOFs [39, 45, 52-58].

\subsection{Synthesis of $P S Q$ nanoparticles}

PSQ nanoparticles are hybrid materials formed via hydrolysis and condensation bis(trialkoxysilanes) $\left.\left(\left(\mathrm{R}^{\prime} \mathrm{O}\right)_{3} \text {-Si-R-Si-( } \mathrm{OR}^{\prime}\right)_{3}\right)$ via sol-gel reactions. As a homopolymer of ( $\mathrm{R}$ $\left.{ }^{\prime} \mathrm{O}\right)_{3}$-Si-R-Si-(OR') $)_{3}$, PSQ nanoparticles allow much higher drug loadings than silica-based materials and their physicochemical properties can be easily tuned by changing the monomer properties. For example, PSQ particles carrying a platinum complex, $\left.\left[\mathrm{Pt}(\mathrm{dach}) \mathrm{Cl}_{2} \text { (triethoxysilylpropyl succinate }\right)_{2}\right]$, were synthesized via controlled hydrolysis and condensation, and further surface-modified with polyethylene glycol (PEG) and anisamide for active targeting to cancer cells (Figure 3) [39, 59].

\subsection{Synthesis of hybrid mesoporous silica (MSN), gold, and iron oxide nanoparticles}

\subsubsection{Synthesis of hybrid mesoporous silica nanoparticles (MSNs)-} Mesoporous silica nanoparticles (MSN), such as 2D hexagonal MCM-41 (Mobile Crystalline Material) and 3D cubic SBA-15 (Santa Barbara Amorphous) nanoparticles, are silica-based porous materials with hundreds of empty channels (mesopores). These mesopores can be used to encapsulate and/or absorb bioactive molecules [60]. The tunable pore size in the $2-50 \mathrm{~nm}$ range with a narrow distribution and high chemical and thermal stability render them useful for drug delivery and biomedical applications [60-62].

MSNs are typically synthesized via base-catalyzed hydrolysis and condensation of tetraethoxysilane in the presence of the cetyltrimethyammonium bromide (CTAB) template. The MSN particles are then treated with a (trialkoxy)silane containing a functional group that can be used to attach polymers, peptide target liagnds, or small interfering RNAs (siRNAs) as illustrated in Figure 4a. For example, MSNs were first modified with (3mercaptopropyl)trimethoxysilane to afford the thiol-functionalized MSN-SH. The MSN-SH particles were then treated with 2,2-dipyridyl disulfide followed by triphenylphosphonium (TPP)-conjugated antibiotics peptide (KLAKLAK) 2 (TPep) to afford the desired MSN-TPep [63]. Loading of topotecan into the channels of MSNs was accomplished by stirring a topotecan hydrochloride solution and MSN-TPep in PBS at room temperature overnight. 
Finally, the pH-responsive anionic poly(ethylene glycol)-blocked-2,3, dimethylmaleic anhydride modified poly(L-lysine) (PEG-PLL(DMA)) was anchored onto the surface of positively charged MSN-TPep nanoparticle by electrostatic interactions to afford the negatively charged MSN-TPep/PEG-PLL(DMA) nanoparticle [63].

2.3.2. Synthesis of hybrid gold nanoparticles-Gold nanoparticles (AuNPs or GNPs) exhibit a plethora of unique properties such as biocompatibility, plasmonic absorption, and easy functionalization with a variety of chemical moieties through thiol groups [64, 65]. As a result, AuNPs have been extensively explored for biosensing [66], imaging [67], and photothermal cancer therapy [68]. The ability to pegylate AuNPs allows them to preferentially accumulate in tumors via the EPR effect [69]. In addition to these intrinsic properties, AuNPs can serve as nanocarriers for the delivery of chemo-and biologic therapeutics to tumors to enable combination therapy [70-74].

AuNPs have been synthesized by a variety of methods, among which citrate-mediated reduction of $\mathrm{HAuCl}_{4}$ is the most commonly used to prepare AuNPs. The most reliable method of AuNP surface modifications, however, relies on thiol-Au interactions; for example, AuNPs can be readily decorated with PEG or DNA via the Au-thiol linkages to realize colloidal stabilization and functionalization. Non-thiolated DNA can also be adsorbed onto the surface of AuNPs via hydrophobic interactions [75] and/or specific chemical bonding between DNA base pairs and the AuNP surface [76]. In addition, positively charged drugs, such as Dox can be non-covalently loaded either directly onto AuNPs [77] or through DNA strands via electrostatic interactions [78]. As depicted in Figure $4 \mathrm{~b}$, AuNPs were mixed with DNA followed by addition of positively charged drug to form hybrid AuNP/DNA/DOX. PEG was then further coated onto the AuNPs via thiol-Au interactions.

2.3.3. Synthesis of hybrid iron oxide nanoparticles-Iron oxide nanoparticles (IONPs) can range in 1 to $100 \mathrm{~nm}$ in sizes and have a favorable biocompatibility in vivo, making them suitable for biomedical applications [79]. Owing to their superparamegnetic properties, IONPs have been extensively used as MRI contrast agents [80], nanocarriers for magnetically targeted drug delivery [81], magnetically triggered drug release [82], and magnetically facilitated gene transfection [83]. Also, magnetic hyperthermia (MHT), which consists of heat generation in tumors via the application of magnetic nanoparticles and an alternating magnetic field (AMF), has shown positive therapeutic outcomes[84-86].

The simplest and most efficient method to generate IONPs is the co-precipitation of $\mathrm{Fe}^{3+}$ and $\mathrm{Fe}^{2+}$ with ammonium hydroxide. For biomedical applications, IONPs are normally coated with surfactants and polymers to improve biocompatibility, prevent agglomeration, and acquire functionality. As shown in Figure 4c, IONPs were first coated with surfactants and polymers followed by the incorporation of therapeutic agents. 


\section{NCPs and NMOFs for combination therapy}

\subsection{Co-delivery of multiple chemotherapeutic agents}

Lin and coworkers reported a Zn NCP (Zn-Oxali\&GMP) carrying both oxaliplatin and gemcitabine monophosphate (GMP) for synergistic combination therapy of pancreatic cancer (Figure 5) [87]. Oxaliplatin, like most Pt drugs, causes cellular DNA strand breaks and induce cell cycle arrest and cell apoptosis, while gemcitabine inhibits DNA synthesis by blocking DNA strand elongation and potentially preventing repair of oxaliplatin-induced DNA damage. Since the two drugs have different mechanisms of action, oxaliplatin and GMP provide synergistic effects. Upon intravenous (i.v.) injection, this NCP exhibits prolonged blood circulation with Pt and GMP blood circulation half-lives of $10.1 \pm 3.3 \mathrm{~h}$ and $8.0 \pm 2.3 \mathrm{~h}$, respectively, minimal mononuclear phagocyte system uptake, and high tumor uptake of $8.8 \pm 2.0 \mathrm{ID} \% / \mathrm{g} 24$ hours post injection. The NCP particles thus enable the codelivery of two chemotherapeutics that have distinctive mechanisms of action. After $48 \mathrm{~h}$ of incubation, NCP carrying oxaliplatin and GMP exhibited significantly enhanced anticancer efficacy against AsPc-1 and BxPc-3 cells, with $\mathrm{IC}_{50}$ values that are about 5-fold, 2-fold, and 4-fold lower than free oxaliplatin, NCP carrying oxaliplatin alone, free GMP, and NCP carrying GMP alone, respectively. The enhanced anticancer efficacy of the NCPs carrying two chemotherapeutics was ascribed to the synergistic effect exerted by oxaliplatin and GMP.

The enhanced anticancer efficacy of this NCP combination therapy was demonstrated in two human pancreatic cancer mouse models. For the BxPC-3 tumor model, the tumor growth in the combination NCP group was effectively suppressed with the average tumor size increasing 1.7-fold, in comparison to the increase of 3.6 14.3-folds in for the control groups. The tumor weight of the combination NCP group was 2.7 times smaller than that of the NCP carrying oxaliplatin alone $(p=0.0342)$ and 16.6 times smaller than that of the NCP carrying GMP alone $(p=0.0031)$. For the AsPC-1 tumor model, the tumor size of the combination NCP group showed only a 3 -fold increase 56 days post injection, whereas the PBS control and free drug combination groups show nearly a 6-fold increase in tumor size $(p=0.00076)$.

\subsection{Co-delivery of chemotherapeutics and biologics}

Unlike most chemotherapeutics, biologics such as small interfering RNAs (siRNAs) are not readily uptaken by cells in their free forms due to their hydrophilicity and high molecular weights. Nanoparticle platforms including liposomes, polyplexes, AuNPs, and IONPs have been explored for the delivery of siRNAs. By taking advantage of their highly modular structures, NMOFs and NCPs have been used to co-deliver siRNA with chemotherapeutics to achieve efficient gene silencing both in vitro and in vivo.

Lin and coworkers reported the first use of NMOFs for the co-delivery of cisplatin and siRNAs and demonstrated the enhanced therapeutic efficacy in cisplatin-resistant ovarian cancer cells (Figure 6) [88]. UiO NMOFs with amino-triphenyldicarboxylic acid (aminoTPDC) as bridging ligands and $\mathrm{Zr}^{4+}$ as metal connecting points were loaded with cisplatin and a pool of siRNAs targeting multidrug resistant genes. Cisplatin and siRNAs were loaded 
at high loading amounts via encapsulation into the NMOF channels and surface coordination between the phosphate groups of siRNAs and $\mathrm{Zr}^{4+}$ metal ions, respectively. siRNA/UiO-Cis NMOFs efficiently delivered both siRNA and cisplatin to human ovarian cancer cells and dramatically decreased the cisplatin $\mathrm{IC}_{50}$ values by an order of magnitude compared to free cisplatin in four cisplatin-resistant human ovarian cancer cells including ES-2, OVCAR-3, SKOV-3, and A2780/CDDP.

In another example, Lin and coworkers demonstrated the in vivo anticancer efficacy of NCPs loaded with cisplatin and pooled siRNAs targeting multidrug resistant genes in a subcutaneous xenograft mouse model of cisplatin-resistant human ovarian cancer (Figure 7) [89]. The Zn-cis NCP was first coated with a cationic lipid layer. Pooled siRNAs targeting drug-resistant genes P-glycoprotein, Bcl-2, and survivin were adsorbed onto the particle surface via electrostatic interactions to yield nanoparticles carrying both cisplatin and siRNAs (Zn-cis/siRNAs) with particle sizes of $\sim 150 \mathrm{~nm}$ and near neutral surface charge. The resulting nanoparticles increased the cellular uptake of cisplatin and siRNAs, enabled efficient endosomal escape, and mediated effective gene silencing in cisplatin-resistant ovarian cancer cells. As a result, the $\mathrm{Zn}$-cis/siRNAs significantly enhanced the chemotherapeutic efficacy as evidenced by the dramatically decreased cisplatin $\mathrm{IC}_{50}$ values (by two-orders of magnitude compared to free cisplatin) in cisplatin-resistant ovarian cancer cells. Local injection of $\mathrm{Zn}$-cis/siRNAs led to significant tumor regression ( $\sim 60 \%$ reduction in tumor volume) in the cisplatin-resistant SKOV-3 subcutaneous xenograft mouse model.

\subsection{Co-delivery of chemotherapeutics and photosensitizer}

Photodynamic therapy (PDT) is an effective anticancer procedure that involves the administration of a tumor-localizing photosensitizer (PS) followed by light activation to generate highly cytotoxic reactive oxygen species (ROS), particularly singlet oxygen $\left({ }^{1} \mathrm{O}_{2}\right)$, which triggers cell apoptosis and necrosis [90-97]. Lin and coworkers developed Zn-cisbased core-shell nanoparticles carrying high payloads of cisplatin and the photosensitizer pyrolipid, Zn-cis@ pyrolipid, for combined chemotherapy and PDT [98]. Zn-cis@pyrolipid releases cisplatin and pyrolipid in a triggered manner and synergistically induced cancer cell apoptosis and necrosis. Zn-cis@ pyrolipid showed high uptake and accumulation in cancer cells. Negligible cisplatin efflux from cancer cells was observed for Zn-cis@ pyrolipid in a 24-h incubation period.

This result might be attributed to the incorporation of pyrolipid into cell membranes instead of being recycled out of the cells after disassociation from the solid core of $\mathrm{Zn}$ cis@pyrolipid during endocytosis, which partially modified the cell membrane. After i.v. injection to tumor bearing mice, Zn-cis@ pyrolipid exhibited prolonged blood circulation half-lives for both of cisplatin and pyrolipid at $9.0 \pm 1.8 \mathrm{~h}$ and $6.7 \pm 2.2 \mathrm{~h}$, respectively. As a result of its excellent pharmacokinetics and decreased efflux of cisplatin and pyrolipid, $\mathrm{Zn}$ cis@pyrolipid achieved as high as $23 \pm 2.4$ ID\%/g cisplatin accumulation in the tumor $24 \mathrm{~h}$ post i.v. injection. In a subcutaneous xenograft mouse model of resistant head and neck cancer, Zn-cis@pyrolipid showed superior efficacy in 83\% tumor regression (tumor volume) at low drug doses (Figure 8). However, $\mathrm{Zn}$-cis carrying cisplatin alone failed to achieve anticancer efficacy because the tumor model is resistant to cisplatin treatment. 


\section{PSQ for combined chemotherapy and radiotherapy}

Chemoradiotherapy is performed in the clinic for the treatment of multiple cancer types because of its significantly enhanced therapeutic efficacy compared to either chemotherapy or radiotherapy alone. Lin and coworkers reported a PSQ-cis nanoparticle carrying a cisplatin prodrug, $c, c, t-\mathrm{Pt}\left(\mathrm{NH}_{3}\right)_{2} \mathrm{Cl}_{2}(\mathrm{OH})_{2}$, and its use in chemoradiotherapy (Figure 9) [99]. The PSQ-cis nanoparticles carried $42 \mathrm{wt} \%$ of cisplatin and were postsynthetically PEGylated. The chemoradiotherapeutic efficacy of 150-nm nanoparticles was evaluated in vitro and in vivo in human non-small cell lung cancer cells and subcutaneous xenograft mouse models. At a cisplatin dose of $1 \mathrm{mg} / \mathrm{kg}$ and a radiation dose of $10 \mathrm{~Gy}$, the PSQ nanoparticles demonstrated superior anticancer efficacy than free cisplatin and radiation alone in two subcutaneous xenograft mouse models of human non-small cell lung cancer H460 and A549.

\section{MSNs for combination therapy of cancer}

MSNs were employed as nanocarriers for the simultaneous delivery of anticancer drugs and siRNAs to treat drug resistant cancer. Meng et al showed that decoration of the MSN surface with a phosphonate group facilitates the loading of Dox to the porous interior via electrostatic interactions (Figure 10). The attachment of polyethylenimine (PEI) to the outer surface allowed the MSNs to deliver anti-P-gp siRNA simultaneously. Co-delivery of Dox and anti-P-gp siRNA led to synergistically improved cell killing effect in KB-V1 resistant cancer cells by suppressing the activity of efflux transporter P-gp, re-sensitizing cells to Dox treatment [100]. More recently, the same group reported that MSNs functionalized with a polyethyleneimine polyethylene glycol (PEI-PEG) copolymer allowed the particles to circulate for a longer period of time to lead to enhanced tumor uptake (Figure 10). The combination of Dox and P-gp siRNA in MSNs resulted in superior tumor growth inhibition (80\%) in a MCF-7/MDR xenograft model in comparison to free Dox (17\%) or the MSNs packed with either Dox (62\%) or P-gp siRNA alone (0\%). Furthermore, pronounced P-gp gene knockdown was detected at heterogeneous tumor sites that matched to the areas with significant apoptosis induced by Dox [101].

MSNs were also explored for combined chemotherapy and PDT. Chen and co-workers developed dual $\mathrm{pH}$-responsive MSNs that were sensitive to the tumor extracellular and intercellular $\mathrm{pH}$ stimuli [102]. The silica surface was coated with histidine, which bonded to the acid sensitive PEGylated (tetraphenylporphyrin)zinc (Zn-Por-CA-PEG) via the Znhistidine coordination to provide a gatekeeper to block the nanopores of MSNs. This design prevented the entrapped drug from leaching out at normal tissue, but allowed the MSNs to specifically release the payloads at the tumor site as a result of higher acidity. Once the $\mathrm{pH}$ sensitive bond cis-aconitic anhydride (CA) linking Zn-Por and PEG broke, the surface of $\mathrm{Zn}$-Por became positively charged, facilitating the intracellular uptake of the nanoparticles. Meanwhile, the Zn-Por produced ROS upon light activation, to achieve synergistic PDT and chemotherapy. By combining chemotherapy and PDT, a significantly improved anticancer activity in both HeLa and MCF-7 tumor cells was accomplished. 


\section{Gold nanoparticles for combination therapy}

\subsection{Gold nanoparticles for combined chemotherapy and photothermal therapy}

Zhang and coworkers developed a core/shell nanoparticle composed of Au nanoshell and 10-hydroxycamptothecin (HCPT-NPs) for combined chemotherapy and photothermal therapy of breast cancer [103] (Figure 11). With an extremely high HCPT loading at 63.7\% along with the strong photothermal ability delivered by Au nanoshells, a potent synergism was achieved both in vitro and in vivo. The HCPT-NPs had a favorable pharmacokinetics and biodistribution with a blood circulation half-life of $\sim 3.5 \mathrm{~h}$ and $32.08 \%$ injected dose/g tumor $24 \mathrm{~h}$ post-injection. At an irradiation power density of $1 \mathrm{~W} \mathrm{~cm}^{-2}$ for 10 minutes, the core-shell nanoparticle led to complete tumor remission in $4 \mathrm{~T} 1$ breast syngeneic mouse model without significant mouse weight loss and tumor relapse. This excellent therapeutic efficacy was ascribed to the potent synergistic effect via photothermal therapy by Au nanoshell and apoptosis by HCPT. Minimal systemic toxicity was observed in the mice that had been i.v. administered with the particles.

Li and co-workers used DNA-wrapped AuNRs (GNR) with co-delivered Doxorubicin (DOX) (GNR@DOX) to treat metastatic breast cancer by combining chemotherapy and photothermal ablation [78] (Figure 12). GNR@DOX increased the local temperature substantially and efficiently liberated the loaded DOX upon laser irradiation. Combination of DOX and photothermal effect led to a significantly improved anticancer cell proliferation in vitro. As shown in Figure $12 \mathrm{a} \& \mathrm{~b}$, approximately $35^{\circ} \mathrm{C}$ and $30^{\circ} \mathrm{C}$ increase in temperature was discerned in tumors injected by GNR and GNR@DOX, respectively, after being irradiated with $655 \mathrm{~nm}$ laser at a power output of $1.0 \mathrm{~W} \mathrm{~cm}-2$ for 80 seconds. Two hours after intratumoral administration of GNR@DOX with irradiation at a laser power output of $1.0 \mathrm{~W} \mathrm{~cm}^{-2}$ for 2 minutes led to a significantly enhanced breast tumor growth inhibition in an orthotropic 4T1 mammary tumor model. In addition, the associated distant metastasis was also notably suppressed in GNR@DOX/laser-treated tumor as evidenced in Figure 12c, which is in a sharp contrast to the wide distribution of luciferase signal found surrounding the primary tumors treated with PBS, DOX, GNR-DNA, and GNR@DOX without irradiation. The greatly improved antitumor proliferation and the inhibition of metastasis in primary 4T1 tumors could be due to the synergistic effect between the apoptosis induced by DOX and necrosis attributed to NIR laser irradiation. This postulation was further substantiated by the H\&E, Ki-67 immunohistochemistry, and TUNEL staining assays, in which markedly augmented necrosis, anti-proliferation, as well as apoptosis were noticed in tumors treated by GNR@DOX with laser irradiation. Taken together, these exciting results in metastatic breast tumor by utilizing hybrid GNR@DOX invariably deserves further investigation in future.

Choi and colleagues reported a PEGylated multi-functional hollow gold nanoparticle (HGNP) carrying Dox (Dox-HGNP) for the treatment of A549 lung cancer [104] (Figure 13). Dox can be efficiently released from the nanoparticles upon NIR irradiation. Meanwhile, the heat generated from Au NIR absorption can lead to hyperthermia-induced toxicity in tumor sites. Moreover, HGNP was able to sensitize A549 cells to 6 MV X-ray radiation (typically used in clinics for radiotherapy), as evidenced by the radiation-induced 
DNA double-strand breaks in A549 cells. Combination of Dox, heat, radiation exhibited the highest level killing of the cancer cells in vitro. More importantly, this combination therapy in Dox-HGNP resulted in a superior tumor growth inhibition in A549 xenograft mouse model.

\section{Iron oxide nanoparticles for combination therapy}

Wang and colleagues reported a multifunctional nanoparticle composed of supraparamagnetic $\mathrm{Fe}_{3} \mathrm{O}_{4}$ nanoparticles and chemotherapeutics DNR and 5-BrTet $\left(\mathrm{Fe}_{3} \mathrm{O}_{4}\right.$ MNP-DNR-5-BrTet), an inhibitor of P-gp and anti-apoptotic proteins, for concomitant chemotherapy and hyperthermia [105] (Figure 14). Significant temperature increase was observed in tumors treated by both $\mathrm{Fe}_{3} \mathrm{O}_{4}$-MNP and $\mathrm{Fe}_{3} \mathrm{O}_{4}$-MNP-DNR-5-BrTet. In resistant human K562/A02 leukemia xenograft mouse model, tumors treated with $\mathrm{Fe}_{3} \mathrm{O}_{4}$-MNPDNR-5-BrTet had about $80 \%$ tumor reduction after day 12, dramatically higher level of tumor growth suppression or regression when compared to DNR, DNR plus 5-BrTet, and $\mathrm{Fe}_{3} \mathrm{O}_{4}$-MNP. The combination of chemotherapy, hyperthermia, and inhibition of multidrug resistance protein could have played a central role in the superb antitumor efficacy. The ability of $\mathrm{Fe}_{3} \mathrm{O}_{4}$-MNP-DNR-5-BrTet to overcome the drug resistance was confirmed by the markedly reduced $\mathrm{P}-\mathrm{gp}$ and $\mathrm{Bcl}-2$ expression, and significantly increased Bax and caspase-3 expression in tumors.

Yang and coworkers developed a hybrid IONP composed of iron oxide nanoparticle core conjugated with targeting ligands and double-stranded DNA nanocassettes containing a U6 promoter and a shRNA gene for in vivo siRNA expression. Delivery of survivin siRNA expressing nanocassettes into tumor cells has been demonstrated to effectively induce apoptotic cell death and sensitizes cells to gemcitabine-based chemotherapy [106].

\section{Conclusions and outlook}

Hybrid nanoparticles have emerged as a promising platform for developing novel nanomedicines. In particular, their synthetic tunability has allowed the design of many nanoparticles for the co-delivery of multiple therapeutic agents or modalities. All of the four hybrid nanoparticle platforms discussed here have interesting attributes for accommodating the loading of multiple therapeutics/modalities and their temporally and spatially controlled release to maximize the synergy between the different therapeutics and/or modalities. Among them, NCPs and NMOFs appear to provide the most versatile platforms for combination therapy of cancer. In spite of their very early stage of development, NMOFs and NCPs have already shown significant promise in combination therapy of mulitpl cancer typs to synergistically enhanced anticancer efficacy in animal models.

In the next stage, efforts need to be devoted to further enhnace the in vivo performance of hybrid nanoparticles. The surface properties of hybrid nanoparticles need to be optimized in order to achieve prolonged blood circulation and selective tumor targeting after systemic administration. Drugs typically have different pharmacokinetic properties, which often makes it difficult to obtain the optimal dose and might even increase the chances of adverse side effects. Therefore, the nanoparticle formulations need to be fine-tuned to obtain optmized therapeutic combinations and dosing schedules. The highly modular nature of 
NCP synthesis will allow the fine-tuning of the loading and release of different drugs in the same nanoparticle delivery vehicle. Compared to delivering multiple therapies by different delivery systems, accomodating multiple therapies into one single delivery vehicle has several advantages, including reduced manufacture cost, improved patient compliance, and easy-to-monitor release, pharmacokinetics, and biodistribution of different drugs. Finally, systematic evaluations of the Absorption-Distribution-Metabolism-Excretion (ADME) behaviors of hybrid nanoparticles are needed in order to understand their in vivo toxicity profiles. With optimized formulations, surface properties, and ADME behaviors, we believe hybrid nanoparticles can enable effective combination therapy of cancer to bridge the gap between preclinical animal results and human clinical outcomes. Hybrid nanoparticles are expected to have a bright futrue in nanomedicine.

\section{Supplementary Material}

Refer to Web version on PubMed Central for supplementary material.

\section{Acknowledgments}

We thank NIH (U01-CA151455) and the University of Chicago Medicine Comprehensive Cancer Center (NIH CCSG: P30 CA014599) for funding support.

\section{References}

1. Davis ME, Chen Z, Shin DM. Nanoparticle therapeutics: an emerging treatment modality for cancer. Nat Rev Drug Discov. 2008; 7:771-782. [PubMed: 18758474]

2. Li SD, Huang L. Pharmacokinetics and biodistribution of nanoparticles. Mol Pharmaceut. 2008; 5:496-504.

3. Martinez JO, Chiappini C, Ziemys A, Faust AM, Kojic M, Liu XW, Ferrari M, Tasciotti E. Engineering multi-stage nanovectors for controlled degradation and tunable release kinetics. Biomaterials. 2013; 34:8469-8477. [PubMed: 23911070]

4. Wang X, Chen HR, Zheng YY, Ma M, Chen Y, Zhang K, Zeng DP, Shi JL. Au-nanoparticle coated mesoporous silica nanocapsule-based multifunctional platform for ultrasound mediated imaging, cytoclasis and tumor ablation. Biomaterials. 2013; 34:2057-2068. [PubMed: 23246067]

5. Davies CDL, Lundstrom LM, Frengen J, Eikenes L, Bruland OS, Kaahus O, Hjelstuen MHB, Brekken C. Radiation improves the distribution and uptake of liposomal doxorubicin (Caelyx) in human osteosarcoma xenografts. Cancer research. 2004; 64:547-553. [PubMed: 14744768]

6. Lammers T, Peschke P, Kuhnlein R, Subr V, Ulbriich K, Debus J, Huber P, Hennink W. Storm, Effect of radiotherapy and hyperthermia on the tumor accumulation of HPMA copolymer-based drug delivery systems. J Control Release. 2007; 117:333-341. [PubMed: 17215057]

7. Gottesman MM. Mechanisms of cancer drug resistance. Annual review of medicine. 2002; 53:615627.

8. Cabral H, Kataoka K. Progress of drug-loaded polymeric micelles into clinical studies. J Control Release. 2014; 190:465-476. [PubMed: 24993430]

9. Dipetrillo T, Milas L, Evans D, Akerman P, Ng T, Miner T, Cruff D, Chauhan B, Iannitti D, Harrington D, Safran H. Paclitaxel poliglumex (PPX-Xyotax) and concurrent radiation for esophageal and gastric cancer: a phase I study. American journal of clinical oncology. 2006; 29:376-379. [PubMed: 16891865]

10. Gao XH, Cui YY, Levenson RM, Chung LWK, Nie SM. In vivo cancer targeting and imaging with semiconductor quantum dots. Nat Biotechnol. 2004; 22:969-976. [PubMed: 15258594] 
11. Huang XH, El-Sayed IH, Qian W, El-Sayed MA. Cancer cell imaging and photothermal therapy in the near-infrared region by using gold nanorods. J Am Chem Soc. 2006; 128:2115-2120. [PubMed: 16464114]

12. Gupta AK, Gupta M. Synthesis and surface engineering of iron oxide nanoparticles for biomedical applications. Biomaterials. 2005; 26:3995-4021. [PubMed: 15626447]

13. Shen J, Zhao L, Han G. Lanthanide-doped upconverting luminescent nanoparticle platforms for optical imaging-guided drug delivery and therapy. Adv Drug Deliver Rev. 2013; 65:744-755.

14. Li Z, Huve J, Krampe C, Luppi G, Tsotsalas M, Klingauf J, De Cola L, Riehemann K. Internalization Pathways of Anisotropic Disc-Shaped Zeolite L Nanocrystals with Different Surface Properties in HeLa Cancer Cells. Small. 2013; 9:1809-1820. [PubMed: 23335435]

15. Torchilin VP. Recent advances with liposomes as pharmaceutical carriers. Nat Rev Drug Discov. 2005; 4:145-160. [PubMed: 15688077]

16. Lee CC, MacKay JA, Frechet JMJ, Szoka FC. Designing dendrimers for biological applications. Nat Biotechnol. 2005; 23:1517-1526. [PubMed: 16333296]

17. Kataoka K, Harada A, Nagasaki Y. Block copolymer micelles for drug delivery: Design, characterization and biological significance. Adv Drug Deliver Rev. 2012; 64:37-48.

18. Hamidi M, Azadi A, Rafiei P. Hydrogel nanoparticles in drug delivery. Adv Drug Deliv Rev. 2008; 60:1638-1649. [PubMed: 18840488]

19. Bloch ED, Queen WL, Krishna R, Zadrozny JM, Brown CM, Long JR. Hydrocarbon Separations in a Metal-Organic Framework with Open Iron(II) Coordination Sites. Science. 2012; 335:16061610. [PubMed: 22461607]

20. Chen B, Liang C, Yang J, Contreras DS, Clancy YL, Lobkovsky EB, Yaghi OM, Dai S. A Microporous Metal-Organic Framework for Gas-Chromatographic Separation of Alkanes. Angewandte Chemie International Edition. 2006; 45:1390-1393.

21. Li JR, Sculley J, Zhou HC. Metal-Organic Frameworks for Separations. Chemical Reviews. 2011; 112:869-932. [PubMed: 21978134]

22. Rosi NL, Eckert J, Eddaoudi M, Vodak DT, Kim J, O'Keeffe M, Yaghi OM. Hydrogen Storage in Microporous Metal-Organic Frameworks. Science. 2003; 300:1127-1129. [PubMed: 12750515]

23. Suh MP, Park HJ, Prasad TK, Lim DW. Hydrogen Storage in Metal-Organic Frameworks. Chemical Reviews. 2011; 112:782-835. [PubMed: 22191516]

24. Evans OR, Lin W. Crystal Engineering of NLO Materials Based on Metal-Organic Coordination Networks. Acc Chem Res. 2002; 35:511-522. [PubMed: 12118990]

25. Wang C, Zhang T, Lin W. Rational Synthesis of Noncentrosymmetric Metal-Organic Frameworks for Second-Order Nonlinear Optics. Chemical Reviews. 2011; 112:1084-1104. [PubMed: 22070202]

26. Alkordi MH, Liu Y, Larsen RW, Eubank JF, Eddaoudi M. Zeolite-like Metal-Organic Frameworks as Platforms for Applications: On Metalloporphyrin-Based Catalysts. J Am Chem Soc. 2008; 130:12639-12641. [PubMed: 18759392]

27. Fei H, Shin J, Meng YS, Adelhardt M, Sutter J, Meyer K, Cohen SM. Reusable Oxidation Catalysis Using Metal-Monocatecholato Species in a Robust Metal-Organic Framework. J Am Chem Soc. 2014; 136:4965-4973. [PubMed: 24597832]

28. Srirambalaji R, Hong S, Natarajan R, Yoon M, Hota R, Kim Y, Ho Ko Y, Kim K. Tandem catalysis with a bifunctional site-isolated Lewis acid-Bronsted base metal-organic framework, NH2-MIL-101(Al). Chem Commun (Camb). 2012; 48:11650-11652. [PubMed: 23104231]

29. Wang C, Zheng M, Lin W. Asymmetric Catalysis with Chiral Porous Metal-Organic Frameworks: Critical Issues. The Journal of Physical Chemistry Letters. 2011; 2:1701-1709.

30. Yoon M, Srirambalaji R, Kim K. Homochiral Metal-Organic Frameworks for Asymmetric Heterogeneous Catalysis. Chemical Reviews. 2011; 112:1196-1231. [PubMed: 22084838]

31. Zhao M, Ou S, Wu CD. Porous Metal-Organic Frameworks for Heterogeneous Biomimetic Catalysis. Acc Chem Res. 2014; 47:1199-1207. [PubMed: 24499017]

32. Allendorf MD, Houk RJT, Andruszkiewicz L, Talin AA, Pikarsky J, Choudhury A, Gall KA, Hesketh PJ. Stress-Induced Chemical Detection Using Flexible Metal-Organic Frameworks. J Am Chem Soc. 2008; 130:14404-14405. [PubMed: 18841964] 
33. Hu Z, Deibert BJ, Li J. Luminescent metal-organic frameworks for chemical sensing and explosive detection. Chemical Society Reviews. 2014; 43:5815-5840. [PubMed: 24577142]

34. Kent CA, Liu D, Ma L, Papanikolas JM, Meyer TJ, Lin W. Light Harvesting in Microscale MetalOrganic Frameworks by Energy Migration and Interfacial Electron Transfer Quenching. J Am Chem Soc. 2011; 133:12940-12943. [PubMed: 21776996]

35. Kent CA, Mehl BP, Ma L, Papanikolas JM, Meyer TJ, Lin W. Energy Transfer Dynamics in Metal-Organic Frameworks. J Am Chem Soc. 2010; 132:12767-12769. [PubMed: 20735124]

36. Wang C, Xie Z, deKrafft KE, Lin W. Doping Metal-Organic Frameworks for Water Oxidation, Carbon Dioxide Reduction, and Organic Photocatalysis. J Am Chem Soc. 2011; 133:1344513454. [PubMed: 21780787]

37. Zhang T, Lin W. Metal-organic frameworks for artificial photosynthesis and photocatalysis. Chemical Society Reviews. 2014; 43:5982-5993. [PubMed: 24769551]

38. Della Rocca J, Lin W. Nanoscale Metal-Organic Frameworks: Magnetic Resonance Imaging Contrast Agents and Beyond. Eur J Inorg Chem. 2010:3725-3734.

39. Della Rocca J, Liu D, Lin W. Nanoscale metal-organic frameworks for biomedical imaging and drug delivery. Acc Chem Res. 2011; 44:957-968. [PubMed: 21648429]

40. Huxford RC, Della Rocca J, Lin W. Metal-organic frameworks as potential drug carriers. Current opinion in chemical biology. 2010; 14:262-268. [PubMed: 20071210]

41. Lin W, Rieter WJ, Taylor KM. Modular synthesis of functional nanoscale coordination polymers. Angew Chem Int Edit. 2009; 48:650-658.

42. Liu D, Lu K, Poon C, Lin W. Metal-organic frameworks as sensory materials and imaging agents. Inorganic Chemistry. 2014; 53:1916-1924. [PubMed: 24251853]

43. McKinlay AC, Morris RE, Horcajada P, Ferey G, Gref R, Couvreur P, Serre C. BioMOFs: metalorganic frameworks for biological and medical applications. Angew Chem Int Edit. 2010; 49:6260-6266.

44. Wang C, Liu D, Lin W. Metal-organic frameworks as a tunable platform for designing functional molecular materials. J Am Chem Soc. 2013; 135:13222-13234. [PubMed: 23944646]

45. Rieter WJ, Pott KM, Taylor KM, Lin W. Nanoscale coordination polymers for platinum-based anticancer drug delivery. J Am Chem Soc. 2008; 130:11584-11585. [PubMed: 18686947]

46. Huxford-Phillips RC, Russell SR, Liu D, Lin W. Lipid-coated nanoscale coordination polymers for targeted cisplatin delivery. RSC advances. 2013; 3:14438-14443. [PubMed: 24058727]

47. Taylor-Pashow KML, Rocca JD, Xie Z, Tran S, Lin W. Postsynthetic Modifications of IronCarboxylate Nanoscale Metal-Organic Frameworks for Imaging and Drug Delivery. J Am Chem Soc. 2009; 131:14261-14263. [PubMed: 19807179]

48. He C, Lu K, Liu D, Lin W. Nanoscale metal-organic frameworks for the co-delivery of cisplatin and pooled siRNAs to enhance therapeutic efficacy in drug-resistant ovarian cancer cells. J Am Chem Soc. 2014; 136:5181-5184. [PubMed: 24669930]

49. Rieter WJ, Taylor KML, An HY, Lin WL, Lin WB. Nanoscale metal-organic frameworks as potential multimodal contrast enhancing agents. J Am Chem Soc. 2006; 128:9024-9025. [PubMed: 16834362]

50. Liu D, Poon C, Lu K, He C, Lin W. Self-assembled nanoscale coordination polymers with trigger release properties for effective anticancer therapy. Nature Communications. 2014; 5:4182.

51. Huxford RC, deKrafft KE, Boyle WS, Liu D, Lin W. Lipid-coated nanoscale coordination polymers for targeted delivery of antifolates to cancer cells. Chem Sci. 2012; 3:198-204.

52. Taylor KML, Jin A, Lin W. Surfactant-assisted synthesis of nanoscale gadolinium metal-organic frameworks for potential multimodal imaging. Angewandte Chemie-International Edition. 2008; 47:7722-7725.

53. Taylor-Pashow KML, Della Rocca J, Huxford RC, Lin W. Hybrid nanomaterials for biomedical applications. Chem Commun (Camb). 2010; 46:5832-5849. [PubMed: 20623072]

54. Dekrafft KE, Xie Z, Cao G, Tran S, Ma L, Zhou OZ, Lin W. Iodinated Nanoscale Coordination Polymers as Potential Contrast Agents for Computed Tomography. Angewandte ChemieInternational Edition. 2009; 48:9901-9904. 
55. Horcajada P, Chalati T, Serre C, Gillet B, Sebrie C, Baati T, Eubank JF, Heurtaux D, Clayette P, Kreuz C, Chang JS, Hwang YK, Marsaud V, Bories PN, Cynober L, Gil S, Ferey G, Couvreur P, Gref R. Porous metal-organic-framework nanoscale carriers as a potential platform for drug delivery and imaging. Nat Mater. 2010; 9:172-178. [PubMed: 20010827]

56. Miller SR, Heurtaux D, Baati T, Horcajada P, Greneche JM, Serre C. Biodegradable therapeutic MOFs for the delivery of bioactive molecules. Chem Commun (Camb). 2010; 46:4526-4528. [PubMed: 20467672]

57. He C, Lu K, Liu D, Lin W. Nanoscale Metal-Organic Frameworks for the Co-Delivery of Cisplatin and Pooled siRNAs to Enhance Therapeutic Efficacy in Drug-Resistant Ovarian Cancer Cells. J Am Chem Soc. 2014; 136:5181-5184. [PubMed: 24669930]

58. Nguyen JG, Tanabe KK, Cohen SM. Postsynthetic diazeniumdiolate formation and NO release from MOFs. Crystengcomm. 2010; 12:2335-2338.

59. Vivero-Escoto JL, Rieter WJ, Lau H, Huxford-Phillips RC, Lin W. Biodegradable Polysilsesquioxane Nanoparticles as Efficient Contrast Agents for Magnetic Resonance Imaging. Small. 2013; 9:3523-3531. [PubMed: 23613450]

60. Slowing II, Vivero-Escoto JL, Wu CW, Lin VS. Mesoporous silica nanoparticles as controlled release drug delivery and gene transfection carriers. Adv Drug Deliv Rev. 2008; 60:1278-1288. [PubMed: 18514969]

61. Huo Q, Liu J, Wang LQ, Jiang Y, Lambert TN, Fang E. A new class of silica cross-linked micellar core-shell nanoparticles. J Am Chem Soc. 2006; 128:6447-6453. [PubMed: 16683810]

62. Kortesuo P, Ahola M, Karlsson S, Kangasniemi I, Yli-Urpo A, Kiesvaara J. Silica xerogel as an implantable carrier for controlled drug delivery--evaluation of drug distribution and tissue effects after implantation. Biomaterials. 2000; 21:193-198. [PubMed: 10632401]

63. Luo GF, Chen WH, Liu Y, Lei Q, Zhuo RX, Zhang XZ. Multifunctional Enveloped Mesoporous Silica Nanoparticles for Subcellular Co-delivery of Drug and Therapeutic Peptide. Sci Rep-Uk. 2014; 4

64. Pissuwan D, Niidome T, Cortie MB. The forthcoming applications of gold nanoparticles in drug and gene delivery systems. J Control Release. 2011; 149:65-71. [PubMed: 20004222]

65. Hu M, Chen JY, Li ZY, Au L, Hartland GV, Li XD, Marquez M, Xia YN. Gold nanostructures: engineering their plasmonic properties for biomedical applications. Chemical Society Reviews. 2006; 35:1084-1094. [PubMed: 17057837]

66. Xiao Z, Lie P, Fang Z, Yu L, Chen J, Liu J, Ge C, Zhou X, Zeng L. A lateral flow biosensor for detection of single nucleotide polymorphism by circular strand displacement reaction. Chem Commun (Camb). 2012; 48:8547-8549. [PubMed: 22810628]

67. Wang Y, Chen JT, Yan XP. Fabrication of transferrin functionalized gold nanoclusters/graphene oxide nanocomposite for turn-on near-infrared fluorescent bioimaging of cancer cells and small animals. Analytical chemistry. 2013; 85:2529-2535. [PubMed: 23330548]

68. Cao-Milan R, Liz-Marzan LM. Gold nanoparticle conjugates: recent advances toward clinical applications. Expert opinion on drug delivery. 2014; 11:741-752. [PubMed: 24559075]

69. Agarwal A, Mackey MA, El-Sayed MA, Bellamkonda RV. Remote triggered release of doxorubicin in tumors by synergistic application of thermosensitive liposomes and gold nanorods. ACS nano. 2011; 5:4919-4926. [PubMed: 21591812]

70. Alhasan AH, Patel PC, Choi CH, Mirkin CA. Exosome encased spherical nucleic acid gold nanoparticle conjugates as potent microRNA regulation agents. Small. 2014; 10:186-192. [PubMed: 24106176]

71. Jensen SA, Day ES, Ko CH, Hurley LA, Luciano JP, Kouri FM, Merkel TJ, Luthi AJ, Patel PC, Cutler JI, Daniel WL, Scott AW, Rotz MW, Meade TJ, Giljohann DA, Mirkin CA, Stegh AH. Spherical nucleic acid nanoparticle conjugates as an RNAi-based therapy for glioblastoma. Science translational medicine. 2013; 5 209ra152.

72. Kirpotin DB, Drummond DC, Shao Y, Shalaby MR, Hong K, Nielsen UB, Marks JD, Benz CC, Park JW. Antibody targeting of long-circulating lipidic nanoparticles does not increase tumor localization but does increase internalization in animal models. Cancer research. 2006; 66:6732 6740. [PubMed: 16818648] 
73. Shi X, Wang S, Meshinchi S, Van Antwerp ME, Bi X, Lee I, Baker JR Jr. Dendrimer-entrapped gold nanoparticles as a platform for cancer-cell targeting and imaging. Small. 2007; 3:1245-1252. [PubMed: 17523182]

74. Thaxton CS, Elghanian R, Thomas AD, Stoeva SI, Lee JS, Smith ND, Schaeffer AJ, Klocker H, Horninger W, Bartsch G, Mirkin CA. Nanoparticle-based bio-barcode assay redefines "undetectable" PSA and biochemical recurrence after radical prostatectomy. Proceedings of the National Academy of Sciences of the United States of America. 2009; 106:18437-18442. [PubMed: 19841273]

75. Nelson EM, Rothberg LJ. Kinetics and Mechanism of Single-Stranded DNA Adsorption onto Citrate-Stabilized Gold Nanoparticles in Colloidal Solution. Langmuir. 2011; 27:1770-1777. [PubMed: 21218826]

76. Zhang X, Servos MR, Liu JW. Instantaneous and Quantitative Functionalization of Gold Nanoparticles with Thiolated DNA Using a pH-Assisted and Surfactant-Free Route. Journal of the American Chemical Society. 2012; 134:7266-7269. [PubMed: 22506486]

77. Liang JJ, Zhou YY, Wu J, Ding Y. Gold Nanoparticle-Based Drug Delivery Platform for Antineoplastic Chemotherapy. Curr Drug Metab. 2014; 15:620-631. [PubMed: 24909418]

78. Wang D, Xu Z, Yu H, Chen X, Feng B, Cui Z, Lin B, Yin Q, Zhang Z, Chen C, Wang J, Zhang W, $\mathrm{Li}$ Y. Treatment of metastatic breast cancer by combination of chemotherapy and photothermal ablation using doxorubicin-loaded DNA wrapped gold nanorods. Biomaterials. 2014; 35:83748384. [PubMed: 24996756]

79. Ling D, Lee N, Hyeon T. Chemical synthesis and assembly of uniformly sized iron oxide nanoparticles for medical applications. Acc Chem Res. 2015; 48:1276-1285. [PubMed: 25922976]

80. Ho D, Sun X, Sun S. Monodisperse magnetic nanoparticles for theranostic applications. Acc Chem Res. 2011; 44:875-882. [PubMed: 21661754]

81. Subbiahdoss G, Sharifi S, Grijpma DW, Laurent S, van der Mei HC, Mahmoudi M, Busscher HJ. Magnetic targeting of surface-modified superparamagnetic iron oxide nanoparticles yields antibacterial efficacy against biofilms of gentamicin-resistant staphylococci. Acta biomaterialia. 2012; 8:2047-2055. [PubMed: 22406508]

82. Yoo D, Jeong H, Noh SH, Lee JH, Cheon J. Magnetically triggered dual functional nanoparticles for resistance-free apoptotic hyperthermia. Angew Chem Int Edit. 2013; 52:13047-13051.

83. Park JW, Bae KH, Kim C, Park TG. Clustered magnetite nanocrystals cross-linked with PEI for efficient siRNA delivery. Biomacromolecules. 2011; 12:457-465. [PubMed: 21190334]

84. Bollhorst T, Shahabi S, Worz K, Petters C, Dringen R, Maas M, Rezwan K. Bifunctional submicron colloidosomes coassembled from fluorescent and superparamagnetic nanoparticles. Angew Chem Int Edit. 2015; 54:118-123.

85. Gruttner C, Muller K, Teller J, Westphal F. Synthesis and functionalisation of magnetic nanoparticles for hyperthermia applications, International journal of hyperthermia: the official journal of European Society for Hyperthermic Oncology. North American Hyperthermia Group. 2013; 29:777-789.

86. Hilger I, Kaiser WA. Iron oxide-based nanostructures for MRI and magnetic hyperthermia. Nanomedicine. 2012; 7:1443-1459. [PubMed: 22994960]

87. Poon C, He C, Liu D, Lu K, Lin W. Self-assembled nanoscale coordination polymers carrying oxaliplatin and gemcitabine for synergistic combination therapy of pancreatic cancer. J Control Release. 2015; 201:90-99. [PubMed: 25620067]

88. He C, Lu K, Liu D, Lin W. Nanoscale Metal-Organic Frameworks for the Co-Delivery of Cisplatin and Pooled siRNAs to Enhance Therapeutic Efficacy in Drug-Resistant Ovarian Cancer Cells. J Am Chem Soc. 2014; 136:5181-5184. [PubMed: 24669930]

89. He C, Liu D, Lin W. Self-assembled nanoscale coordination polymers carrying siRNAs and cisplatin for effective treatment of resistant ovarian cancer. Biomaterials. 2015; 36:124-133. [PubMed: 25315138]

90. Jin CS, Cui L, Wang F, Chen J, Zheng G. Targeting-triggered porphysome nanostructure disruption for activatable photodynamic therapy. Advanced healthcare materials. 2014; 3:1240 1249. [PubMed: 24464930] 
91. Lovell JF, Jin CS, Huynh E, MacDonald TD, Cao WG, Zheng G. Enzymatic Regioselection for the Synthesis and Biodegradation of Porphysome Nanovesicles. Angewandte Chemie-International Edition. 2012; 51:2429-2433.

92. Lovell JF, Jin CS, Huynh E, Jin HL, Kim C, Rubinstein JL, Chan WCW, Cao WG, Wang LV, Zheng G. Porphysome nanovesicles generated by porphyrin bilayers for use as multimodal biophotonic contrast agents. Nature Materials. 2011; 10:324-332. [PubMed: 21423187]

93. Carter KA, Shao S, Hoopes MI, Luo D, Ahsan B, Grigoryants VM, Song WT, Huang HY, Zhang GJ, Pandey RK, Geng J, Pfeifer BA, Scholes CP, Ortega J, Karttunen M, Lovell JF. Porphyrinphospholipid liposomes permeabilized by near-infrared light. Nature Communications. 2014; 5

94. Agostinis P, Berg K, Cengel KA, Foster TH, Girotti AW, Gollnick SO, Hahn SM, Hamblin MR, Juzeniene A, Kessel D, Korbelik M, Moan J, Mroz P, Nowis D, Piette J, Wilson BC, Golab J. Photodynamic therapy of cancer: an update. CA: a cancer journal for clinicians. 2011; 61:250 281. [PubMed: 21617154]

95. Castano AP, Mroz P, Hamblin MR. Photodynamic therapy and anti-tumour immunity. Nature reviews Cancer. 2006; 6:535-545. [PubMed: 16794636]

96. Celli JP, Spring BQ, Rizvi I, Evans CL, Samkoe KS, Verma S, Pogue BW, Hasan T. Imaging and photodynamic therapy: mechanisms, monitoring, and optimization. Chemical Reviews. 2010; 110:2795-2838. [PubMed: 20353192]

97. Lovell JF, Liu TW, Chen J, Zheng G. Activatable photosensitizers for imaging and therapy. Chemical Reviews. 2010; 110:2839-2857. [PubMed: 20104890]

98. He C, Liu D, Lin W. Self-assembled core-shell nanoparticles for combined chemotherapy and photodynamic therapy of resistant head and neck cancers. ACS nano. 2015; 9:991-1003. [PubMed: 25559017]

99. Rocca JD, Werner ME, Kramer SA, Huxford-Phillips RC, Sukumar R, Cummings ND, ViveroEscoto JL, Wang AZ, Lin W. Polysilsesquioxane nanoparticles for triggered release of cisplatin and effective cancer chemoradiotherapy. Nanomedicine. 2015; 11:31-38. [PubMed: 25038495]

100. Meng H, Liong M, Xia T, Li Z, Ji Z, Zink JI, Nel AE. Engineered design of mesoporous silica nanoparticles to deliver doxorubicin and P-glycoprotein siRNA to overcome drug resistance in a cancer cell line. ACS nano. 2010; 4:4539-4550. [PubMed: 20731437]

101. Meng H, Mai WX, Zhang H, Xue M, Xia T, Lin S, Wang X, Zhao Y, Ji Z, Zink JI, Nel AE. Codelivery of an optimal drug/siRNA combination using mesoporous silica nanoparticles to overcome drug resistance in breast cancer in vitro and in vivo. ACS nano. 2013; 7:994-1005. [PubMed: 23289892]

102. Yao X, Chen X, He C, Chen L, Chen X. Dual pH-responsive mesoporous silica nanoparticles for efficient combination of chemotherapy and photodynamic therapy. J Mater Chem B. 2015; 3:4707-4714.

103. Li W, Zhang X, Zhou M, Tian B, Yu C, Jie J, Hao X, Zhang X. Functional core/shell drug nanoparticles for highly effective synergistic cancer therapy. Advanced healthcare materials. 2014; 3:1475-1485. [PubMed: 24665009]

104. Park J, Park J, Ju EJ, Park SS, Choi J, Lee JH, Lee KJ, Shin SH, Ko EJ, Park I, Kim C, Hwang JJ, Lee JS, Song SY, Jeong SY, Choi EK. Multifunctional hollow gold nanoparticles designed for triple combination therapy and CT imaging. J Control Release. 2015; 207:77-85. [PubMed: 25863273]

105. Ren Y, Zhang H, Chen B, Cheng J, Cai X, Liu R, Xia G, Wu W, Wang S, Ding J, Gao C, Wang J, Bao W, Wang L, Tian L, Song H, Wang X. Multifunctional magnetic Fe3O4 nanoparticles combined with chemotherapy and hyperthermia to overcome multidrug resistance. International journal of nanomedicine. 2012; 7:2261-2269. [PubMed: 22619560]

106. Cho YS, Lee GY, Sajja HK, Qian WP, Cao ZH, He WL, Karna P, Chen XY, Mao H, Wang YA, Yang L. Targeted Delivery of siRNA-Generating DNA Nanocassettes Using Multifunctional Nanoparticles. Small. 2013; 9:1964-1973. [PubMed: 23292656] 


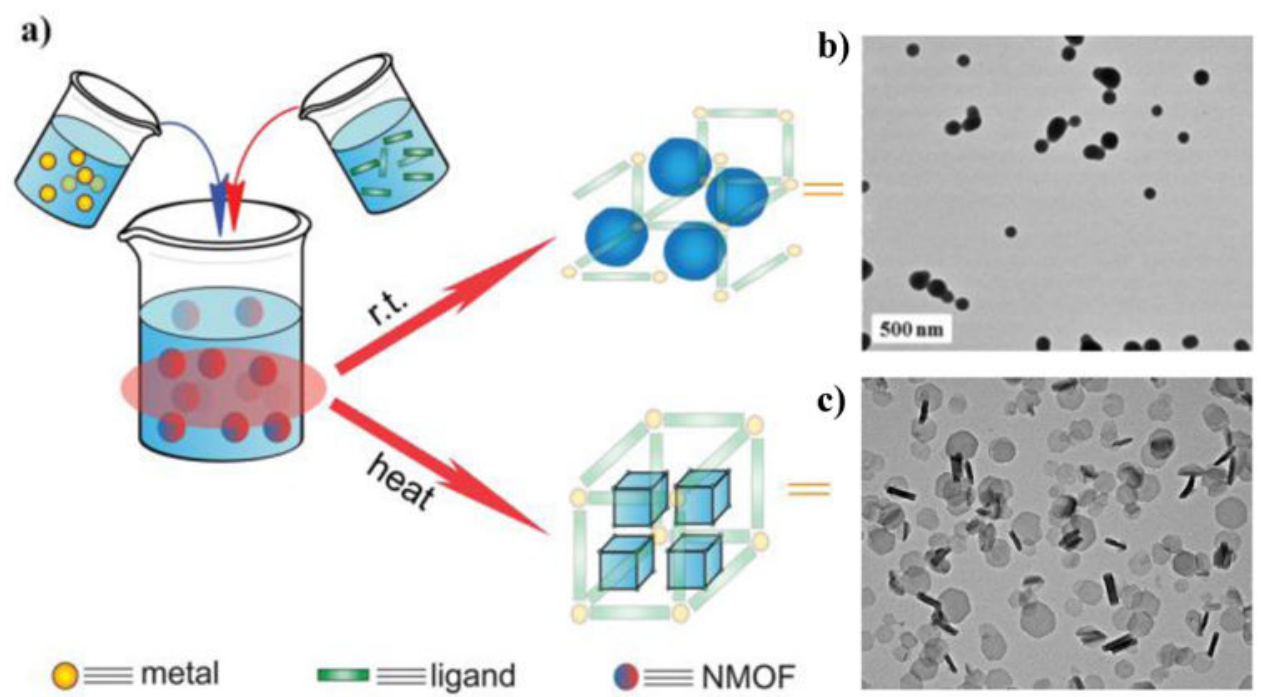

Figure 1.

(a) Surfactant-free synthesis of NMOFs [39]. (b,c) Representative TEM image of NMOFs synthesized by nanoprecipitation (b) [45] and SEM image of NMOFs synthesized by solvothermal method (c) [48]. Reproduced with permission from reference [39, 45, 48]. Copyright (2008, 2014), with permission from American Chemical Society. 

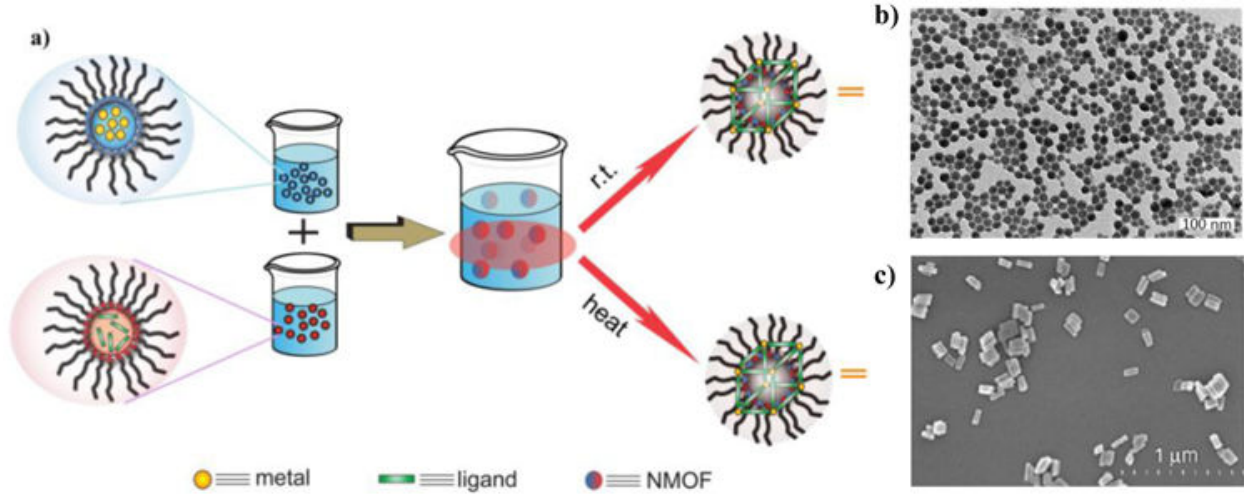

Figure 2.

(a) Surfactant-templated NMOF synthesis based on reverse microemulsions or surfactantassisted solvothermal reactions [39]. (b-c) Representative TEM image showing NMOFs synthesized by surfactant-templated method at room temperature and SEM iamge showing NMOFs synthesized by surfactant-templated method under heating [50, 52]. Reproduced with permission from reference $[39,50,52]$. Copy right (2008), with permission from Wiley Online Library. Copyright (2014), with permission from American Chemical Society. 

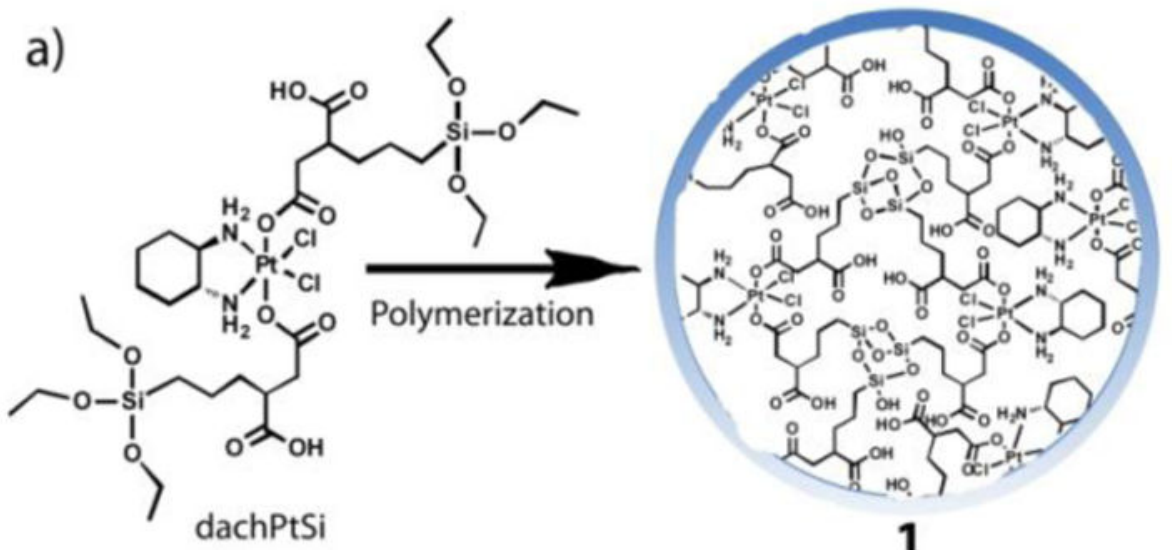

b)

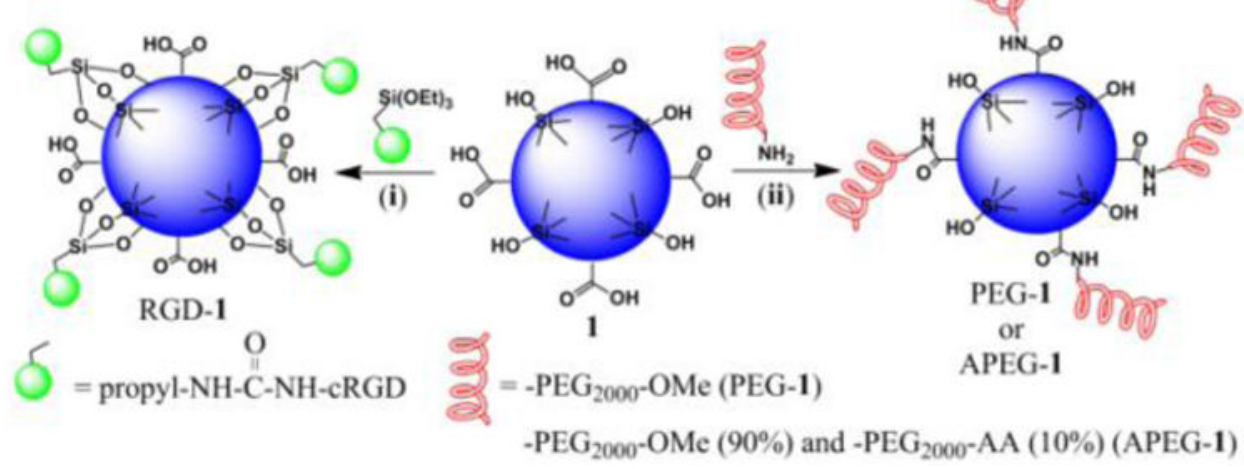

Figure 3.

Schematic representation of the synthesis of PSQ carrying a cisplatin prodrug [39].

Reproduced with permission from reference [39]. Copyright (2014), with permission from Elsevier. 
a)

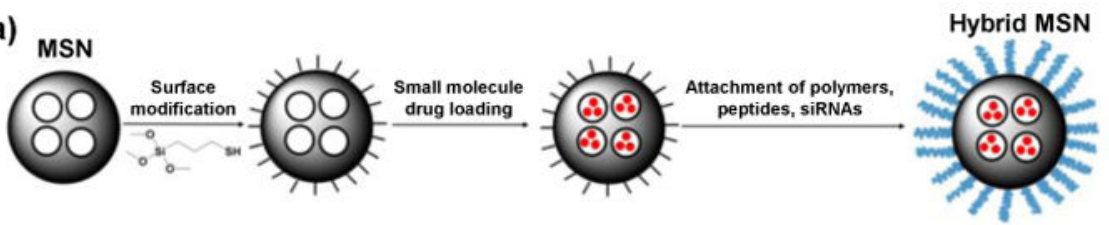
Adsorptios of pootitively
charged drug

Hybrid AuNP

b)

b) AuNP

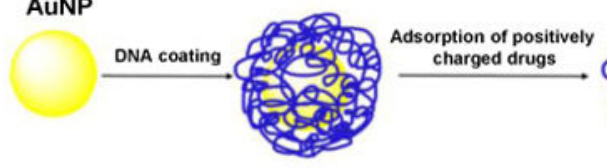

c)
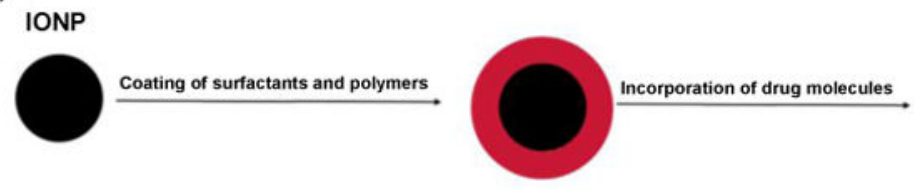

Hybrid IONP

Figure 4.

Schematic illustration of hybrid MSN, AuNP, and IONP synthesis. a) For MSN, the surface is first modified followed by small molecule drug loading, and functionalization of polymers, peptides, and siRNAs. b) For AuNPs, the particles are coated by DNA, followed by the loading of positively charged drugs and then PEGylation. c) For IONPs, the surface is first decorated by surfactants and polymers followed by the incorporation of drug molecules. 
a)
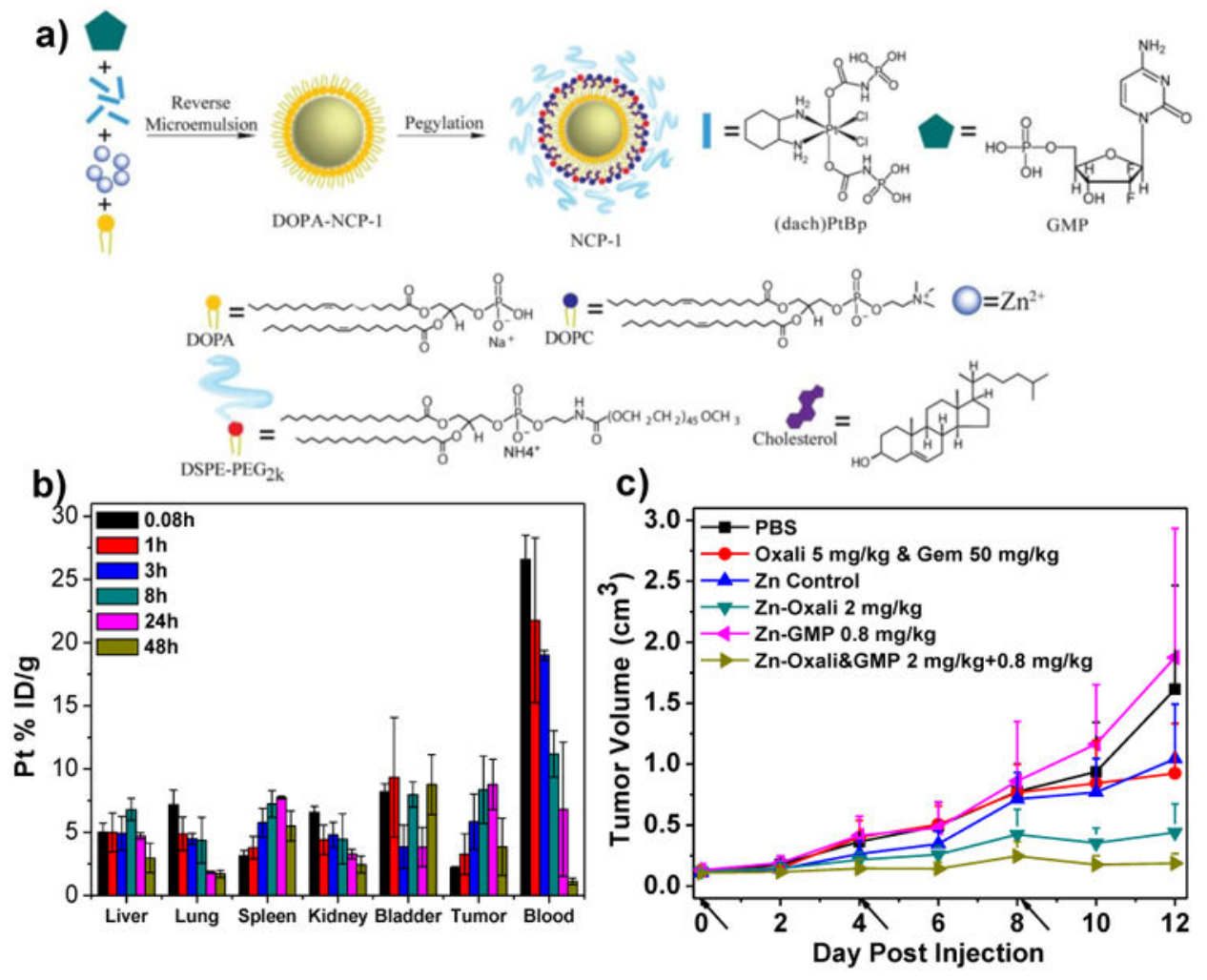

Figure 5.

Zn NCPs carrying oxaliplatin and gemcitabine for combination therapy. (a) Schematic representation of the Zn-Oxali\&GMP synthesis. (b) Pharmacokinetics and biodistribution of Zn-Oxali\&GMP in CT26 tumor bearing mice after i.v. injection. (c) Tumor growth inhibition curves of Zn-Oxali\&GMP NCPs in a subcutaneous xenograft mouse model of human pancreatic cancer BxPC-3. The NCPs were intravenously injected to the mice every four days for a total of three injections. Reproduced with permission from reference [87]. Copyright (2015), with permission from Elsevier.

J Control Release. Author manuscript; available in PMC 2016 December 10. 


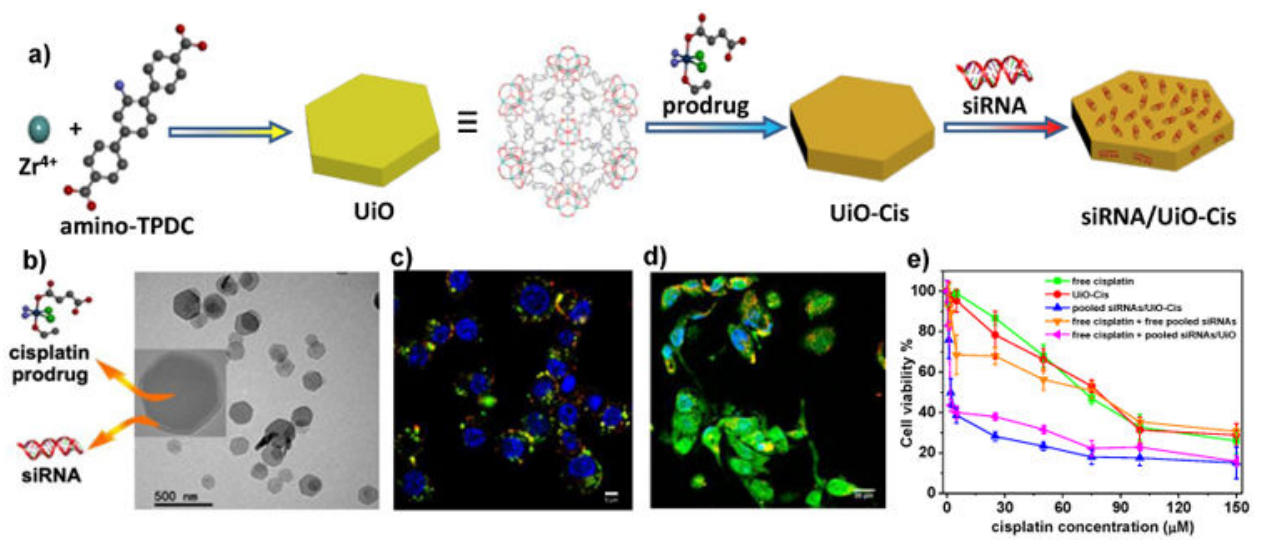

Figure 6.

UiO NMOFs carrying a cisplatin prodrug and siRNAs escaped endosomal entrapment upon entering the cells and induced significant apoptosis in cisplatin-resistant ovarian cancer cells. (a) Schematic presentation of siRNA/UiO-Cis synthesis and drug loading. (b) TEM image of siRNA/UiO-Cis. (c) CLSM image showing that siRNA (TAMRA-labeled, red) successfully escaped from endosomes (Lysotracker Green stained, green). Nuclei were stained with DAPI. Bar=5 $\mu \mathrm{m}$. (d) CSLM image showing the apoptosis induced by siRNA/ $\mathrm{UiO}-\mathrm{Cis}$ in human ovarian cancer cell SKOV-3. The apoptotic cells were stained with Alexa Fluor 488 Annexin V conjugate, and the nuclei were stained with DAPI. Bar=10 $\mu \mathrm{m}$. (e) Cytotoxicity of siRNA/UiO-cis in SKOV-3 cells after 72-h incubation. Reproduced with permission from reference [88]. Copyright (2014), with permission from American Chemical Society. 
a)

c)

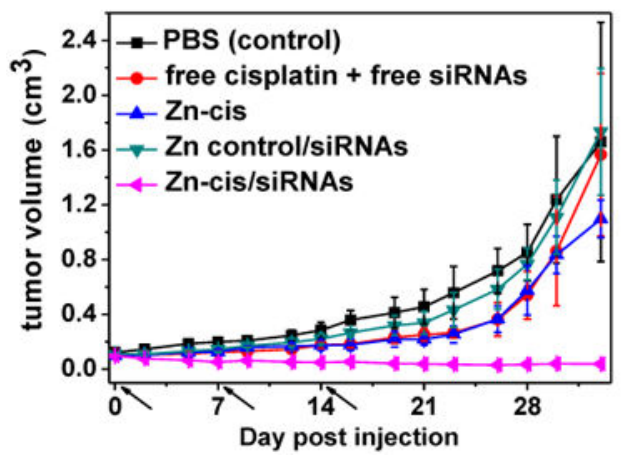

b)

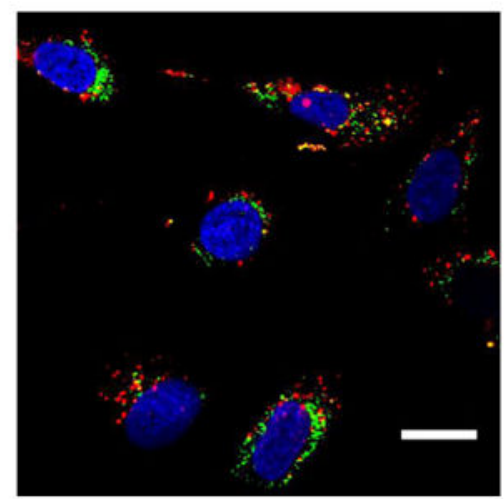

d)

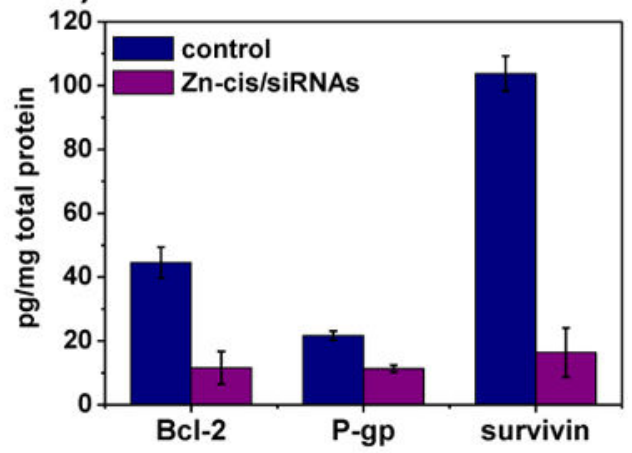

Figure 7.

(a) Schematic presentation of the core-shell structure of Zn-cis/siRNAs. (b) Zn-cis/siRNAs promoted the efficient endosomal escape of siRNA (red fluorescence). The endosome and nuclei were stained with Lysotracker Green (green fluorescence) and DAPI (blue), respectively. Bar=20 $\mu \mathrm{m}$. (c) Tumor growth inhibition curve of Zn-cis/siRNAs. After local administration, $\mathrm{Zn}$-cis/siRNAs showed significant tumor regression in a subcutaneous xenograft mouse model of cisplatin-resistant ovarian cancer. (d) The expression of drug resistant genes in the tumors of mice treated with Zn-cis/siRNAs was significantly downregulated. Reproduced with permission from reference [89]. Copyright (2015), with permission from Elsevier. 
a)

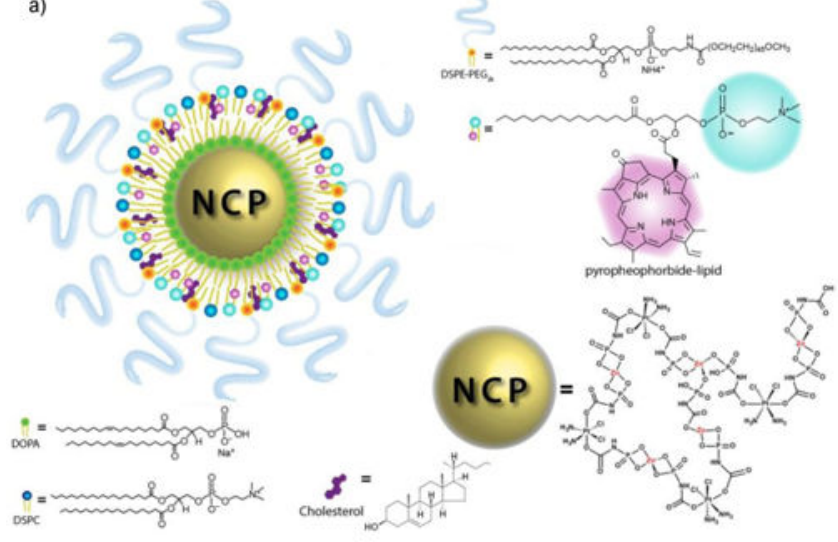

b)

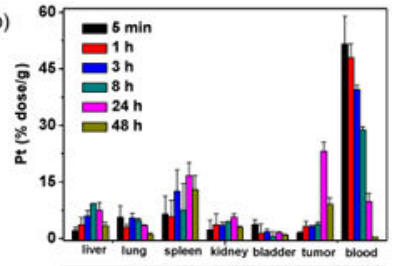

c) $2.4-\mathrm{PBS}_{(+)} \rightarrow-\mathrm{Zn}_{\mathrm{n} \text {-eisepyrolipid (-) }}$

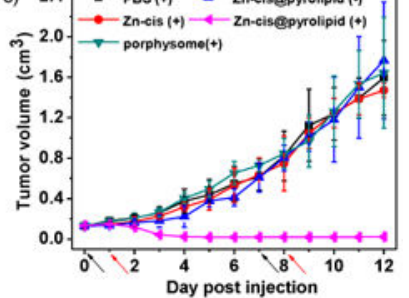

Figure 8.

(a) Schematic showing the composition of the self-assembled NCP@pyrolipid core-shell nanoparticle with PEG and pyrolipid in the outer lipid layer. (b) Pharmacokinetics and biodistribution of Zn-cis@pyrolipid in CT26 tumor bearing mice after intravenous injection. (c) In vivo anticancer efficacy of Zn-cis@pyrolipid. PBS, Zn-cis, porphysome, or Zncis@pyrolipid was intravenously injected to human head and neck cancer SQ20B subcutaneous xenograft murine models at a cisplatin dose of $0.5 \mathrm{mg} / \mathrm{kg}$ or pyrolipid dose of $0.5 \mathrm{mg} / \mathrm{kg}$ followed by irradiation $\left(670 \mathrm{~nm}, 100 \mathrm{~mW} / \mathrm{cm}^{2}\right)$ for $30 \mathrm{~min} 24 \mathrm{~h}$ post injection. Mice receiving Zn-cis@ pyrolipid without irradiation also served as a control. The drug administration and irradiation were performed once a week for twice total. Data expressed as means $\pm \mathrm{SD}(\mathrm{N}=5)$. Black and red arrows in (a) and (d) represent the time of drug administration and irradiation, respectively. "+" and "--" in the figure legends refer to w/and w/o irradiation, respectively. Reproduced with permission from reference [98]. Copyright (2015), with permission from American Chemical Society. 

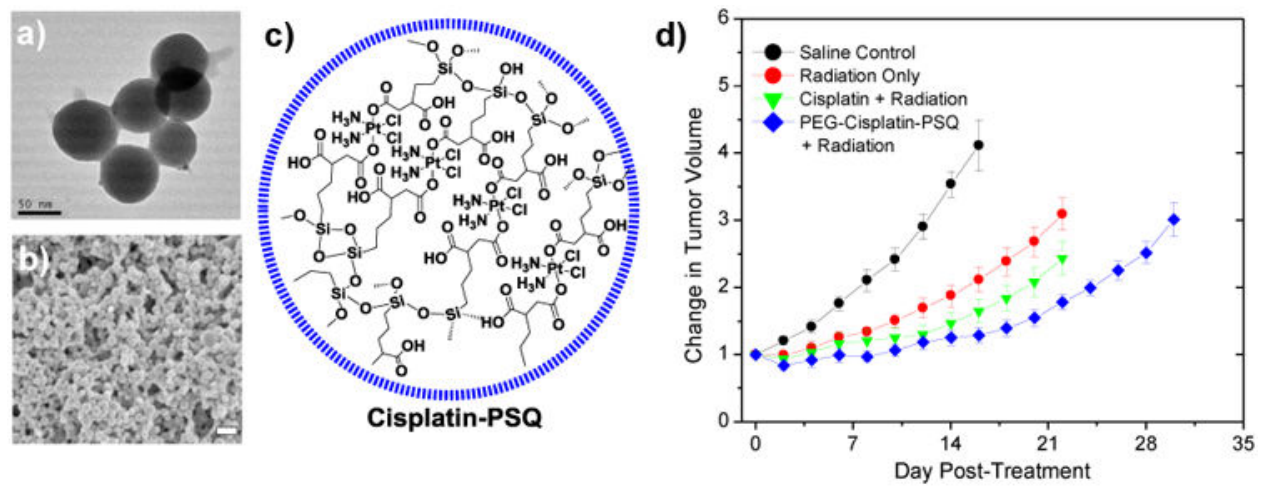

Figure 9.

PSQ nanoparticles carrying a cisplatin prodrug and their anticancer efficacy in human lung cancer xenograft murine models by chemoradiotherapy. TEM (a) and SEM (b) images of cisplatin-PSQ. (c) Schematic showing the chemical structure of cisplatin-PSQ. (d) In vivo chemoradiotherapy efficacy assay against mice bearing A549 xenografts. Cisplatin-PSQ was administrated by tail vein injection. Reproduced with permission from reference [99].

Copyright (2015), with permission from Elsevier. 


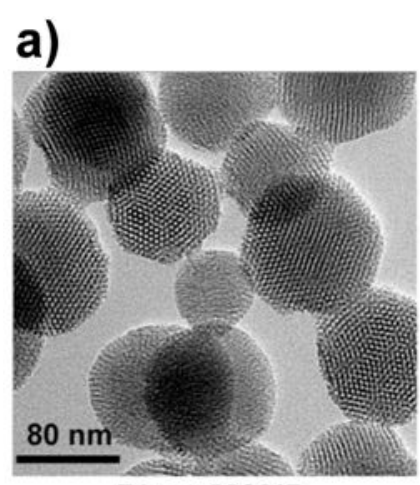

Phos-MSNP

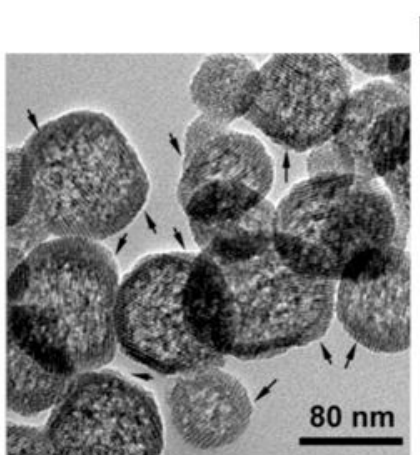

PEI-Phos-MSNP b) $)^{3}$

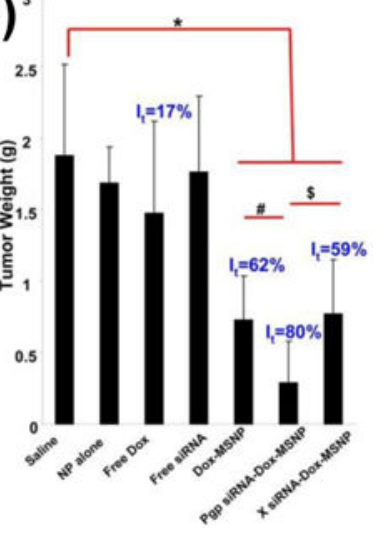

Figure 10.

(a) TEM image of phosphonate-MSNP before and after coating with the $10 \mathrm{kD}$ PEI polymer. The arrows indicate that the polymer decorates the MSNP surface but leaves the porous interior accessible to drug loading. (b) MCF-7/MDR cancer cells were subcutaneously injected into mice 7 days before treatment with MSNP by i.v. injections. The mice received six i.v. injections every 3-6 days for 30 days. Comparison of the tumor inhibition effect of Dox-loaded MSNP containing P-gp siRNA versus other treatment groups: saline, empty MSNP, free Dox, free siRNA, Dox-loaded MSNP without siRNA, and Dox-loaded MSNP containing scrambled siRNA. Reproduced with permission from reference [100, 101]. Copyright (2010 and 2013), with permission from American Chemical Society. 
a)

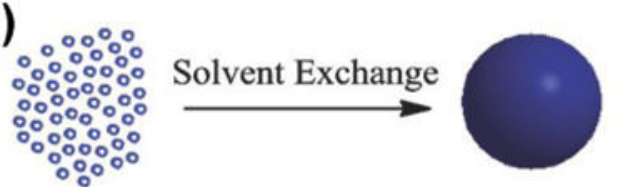

(HCPT)
Surface polymerization modification

Aantrp

PAH

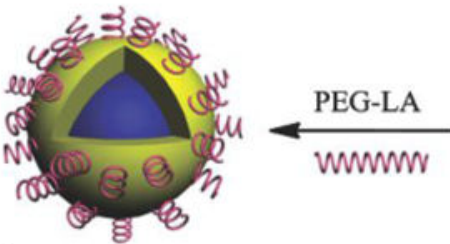

b)

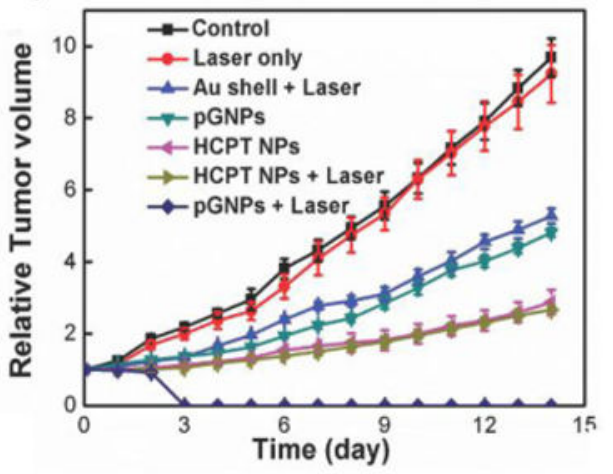

c)

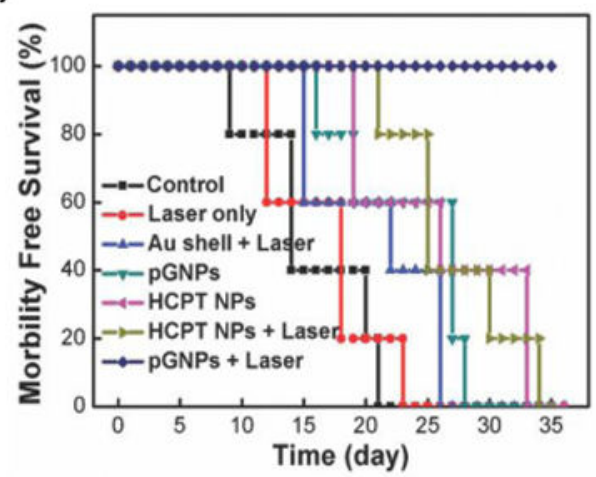

\section{Figure 11.}

(a) Schematic illustration of the preparation of pGNPs. (b) In vivo antitumor activities of control group, laser only without drug injection, hollow Au nanoshells with laser irradiation, pGNPs, HCPT NPs, HCPT NPs with laser irradiation, pGNPs with laser irradiation group on 4T1-tumor-bearing BALB/c mice administered intravenously. Relative tumor volume after treatment administration in different groups was measured. Laser wavelength $=808$ $\mathrm{nm}$; power density $=1 \mathrm{~W} \mathrm{~cm}^{-2}$; irradiation time $=10 \min (24 \mathrm{~h}$ post-injection). (c) Survival curves of mice after various treatments; Mice were removed from the study (considered dead) when their tumor burden exceeded $1000 \mathrm{~mm}^{3}$. Reproduced with permission from reference [103]. Copyright (2014), with permission from Wiley Online Library. 


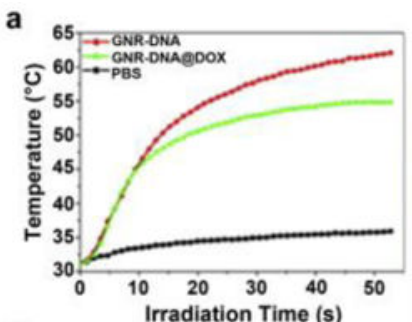

b PBS
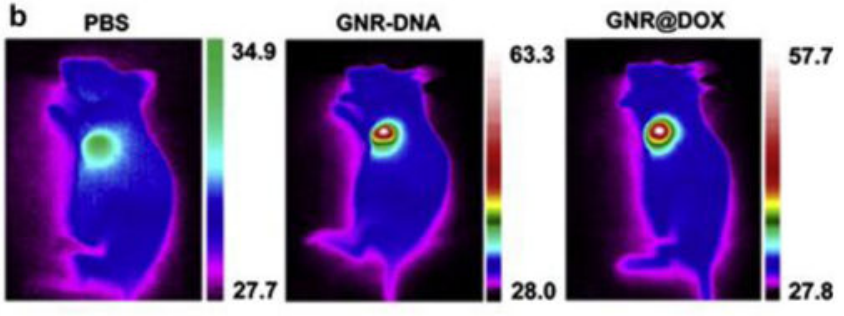

DOX

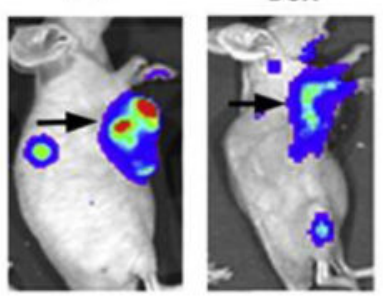

d 2400

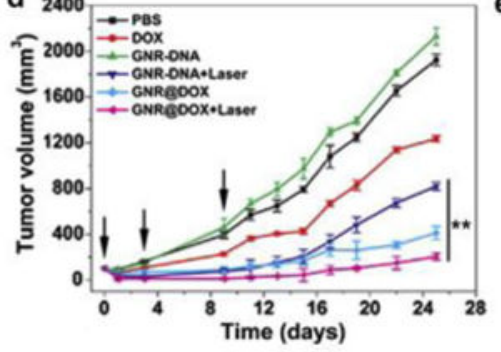

GNR-DNA

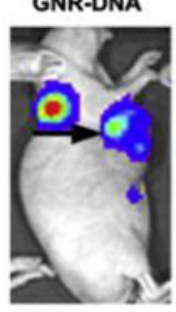

GNR-DNA

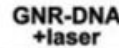

GNR@DOX

GNR@DOX +laser

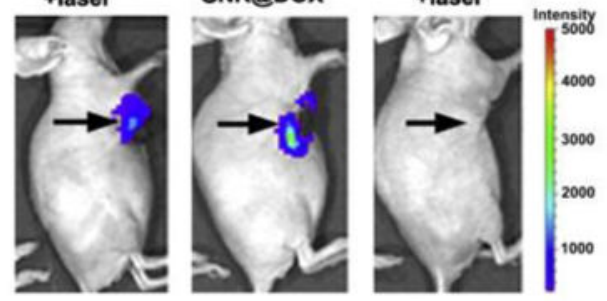

e

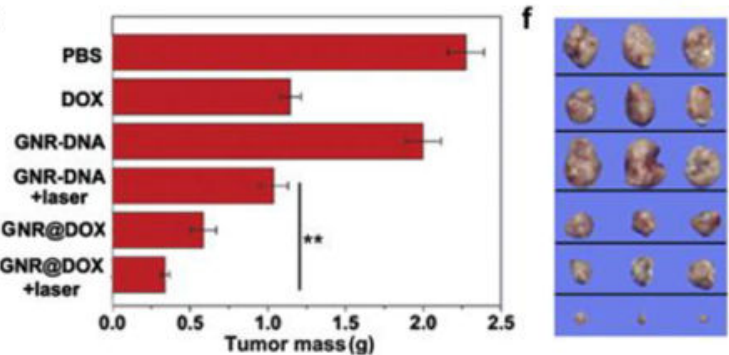

Figure 12.

(a) Temperature elevation and (b) the corresponding infrared thermal images of PBS, GNRDNA or GNR@DOX injected tumors upon $655 \mathrm{~nm}$ laser irradiation for $80 \mathrm{~s}$ (power output of $500 \mathrm{~mW} / \mathrm{cm}$ ); (c) Representative whole-body bioluminescent imaging (BLI) images of 4T1-Luc tumor-bearing mice taken at 25th day post first intraperitoneal injection (the black arrows indicated the position of primary tumors); (d) Tumor growth and (e) tumor weights of mice injected intratumorally with GNR@DOX nanoparticles and treated laser irradiation, the black arrows indicated the time points for GNR@DOX injection and laser irradiation of each mouse group ( $n=6,{ }^{* *} p<0.01$, compared with PBS injected mouse controls); (f) Representative photographs of tumors with different treatment (top to bottom: PBS, DOX, GNR-DNA, GNR-DOX plus NIR irradiation, GNR@DOX or GNR@DOX plus NIR irradiation, respectively). Reproduced with permission from reference [78]. Copyright (2014), with permission from Elsevier. 

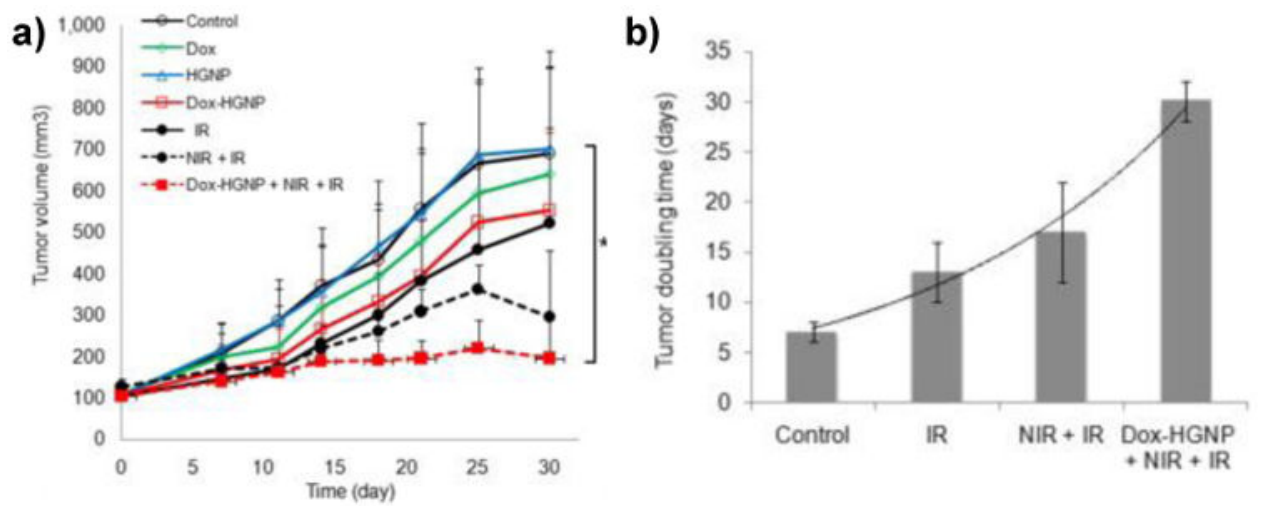

Figure 13.

(a) A549 tumor growth in mice i.v. treated with 10\% trehalose (control), free Dox, HGNP, Dox-HGNP, radiation (IR), NIR laser irradiation and radiation (NIR+IR) and combination of Dox-HGNP, NIR laser irradiation and radiation (Dox-HGNP+ NIR+IR). (b) Tumor doubling time after each treatment corresponding the tumor growth. Reproduced with permission from reference [104]. Copyright (2015), with permission from Elsevier. 

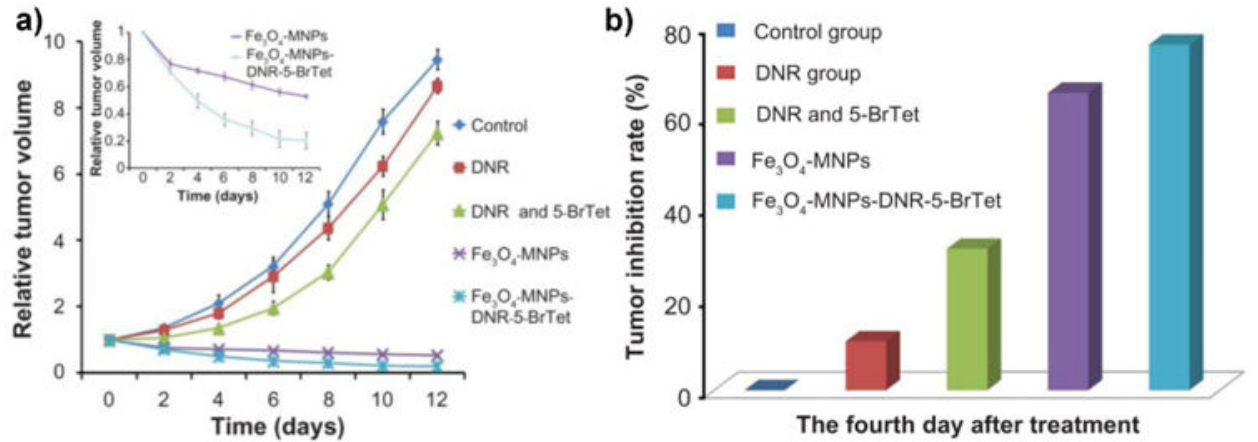

Figure 14.

(a) Relative tumor volume of mice 12 days post various intravenous treatments in resistant human K562/A02 leukemia xenograft mouse model. (b) Tumor inhibition rate of mice at day 4 after treatment. Reproduced with permission from reference [105]. Copyright (2012), with permission from Elsevier. 